\title{
SARS-CoV-2 innate effector associations and viral load in early nasopharyngeal infection
}

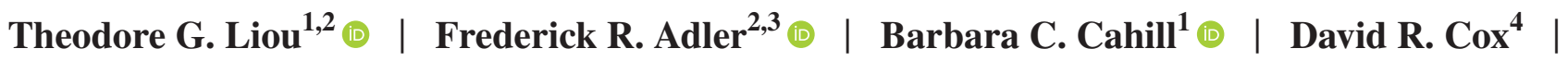

James E. Cox ${ }^{5,6}$ (i) | Garett J. Grant ${ }^{1}$ (D) | Kimberly E. Hanson ${ }^{7,8,9}$ | Stephen C. Hartsell $^{10}$ |

Nathan D. Hatton $^{1}$ ｜ My N. Helms ${ }^{1}$ (D) | Judy L. Jensen ${ }^{1}$ (D) | Christiana Kartsonaki ${ }^{11}$ |

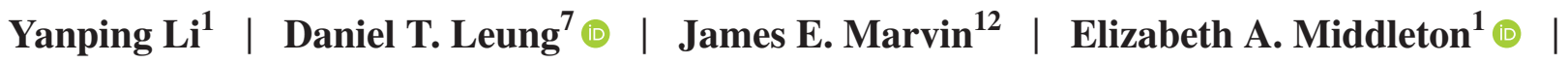

Sandra M. Osburn-Staker $^{6}$ ｜ Kristyn A. Packer ${ }^{1}$ ｜ Salika M. Shakir, ${ }^{8,9}$ | Anne

B. Sturrock $^{1}$ ｜ Keith D. Tardif ${ }^{9}$ ｜Kristi J. Warren ${ }^{1,13}$ (1) | Lindsey J. Waddoups ${ }^{1}$ |

Lisa J. Weaver $^{1}$ | Elizabeth Zimmerman ${ }^{1}$ | Robert Paine III ${ }^{1,13}$ (1)

${ }^{1}$ Division of Respiratory, Critical Care and Occupational Pulmonary Medicine, Department of Internal Medicine, School of Medicine, University of Utah, Salt Lake City, UT, USA

${ }^{2}$ Center for Quantitative Biology, University of Utah, Salt Lake City, UT, USA

${ }^{3}$ Department of Mathematics and School of Biological Sciences, University of Utah, Salt Lake City, UT, USA

${ }^{4}$ Nuffield College, Oxford, UK

${ }^{5}$ Department of Biochemistry, School of Medicine, University of Utah, Salt Lake City, UT, USA

${ }^{6}$ Metabolomics, Proteomics and Mass Spectrometry Core, School of Medicine, University of Utah, Salt Lake City, UT, USA

${ }^{7}$ Division of Infectious Diseases, Department of Internal Medicine, School of Medicine, University of Utah, Salt Lake City, UT, USA

${ }^{8}$ Department of Pathology, University of Utah, Salt Lake City, UT, USA

${ }^{9}$ ARUP Laboratories, Salt Lake City, UT, USA

${ }^{10}$ Division of Emergency Medicine, Department of Surgery, University of Utah, Salt Lake City, UT, USA

${ }^{11}$ Clinical Trial Service Unit \& Epidemiological Studies Unit and Medical Research Council Population Health Research Unit, Nuffield Department of Population Health, University of Oxford, Oxford, UK

${ }^{12}$ Flow Cytometry Core Laboratory, University of Utah Health, Salt Lake City, UT, USA

${ }^{13}$ Department of Veterans Affairs Medical Center, Salt Lake City, UT, USA

\section{Correspondence}

Theodore G. Liou, MD, 26 North Mario Capecchi Drive, Salt Lake City, UT

84132, USA.

Email: ted.liou@utah.edu

Funding information

National Institutes of Health, Grant/ Award Number: S10OD01821001A1;

National Institute of Diabetes and

Digestive and Kidney Diseases, Grant/ Award Number: U54DK11085805;

National Cancer Institute, Grant/Award

Number: 5P30CA042014-24; Ben B and

Iris M Margolis Family Foundation of

\begin{abstract}
COVID-19 causes severe disease with poor outcomes. We tested the hypothesis that early SARS-CoV-2 viral infection disrupts innate immune responses. These changes may be important for understanding subsequent clinical outcomes. We obtained residual nasopharyngeal swab samples from individuals who requested COVID-19 testing for symptoms at drive-through COVID-19 clinical testing sites operated by the University of Utah. We applied multiplex immunoassays, real-time polymerase chain reaction assays and quantitative proteomics to 20 virus-positive and 20 virus-negative samples. ACE-2 transcripts increased with infection (OR $=17.4,95 \% \mathrm{CI}[\mathrm{CI}]=4.78-$ 63.8) and increasing viral $\mathrm{N} 1$ protein transcript load ( $\mathrm{OR}=1.16, \mathrm{CI}=1.10-1.23$ ).
\end{abstract}

This is an open access article under the terms of the Creative Commons Attribution License, which permits use, distribution and reproduction in any medium, provided the original work is properly cited.

(C) 2021 The Authors. Physiological Reports published by Wiley Periodicals LLC on behalf of The Physiological Society and the American Physiological Society 
Utah; Claudia Ruth Goodrich Stevens Endowment Fund at the University of Utah
Transcripts for two interferons (IFN) were elevated, $I F N-\lambda I$ (OR $=71, \mathrm{CI}=7.07-$ $713)$ and $I F N-\lambda 2(\mathrm{OR}=40.2, \mathrm{CI}=3.86-419)$, and closely associated with viral $\mathrm{NI}$ transcripts ( $\mathrm{OR}=1.35, \mathrm{CI}=1.23-1.49$ and $\mathrm{OR}=1.33 \mathrm{CI}=1.20-1.47$, respectively). Only transcripts for $I P-10$ were increased among systemic inflammatory cytokines that we examined ( $\mathrm{OR}=131, C I=1.01-2620)$. We found widespread discrepancies between transcription and translation. IFN proteins were unchanged or decreased in infected samples (IFN- $\gamma$ OR $=0.90 \mathrm{CI}=0.33-0.79$, IFN- $\lambda 2,3 \mathrm{OR}=0.60 \mathrm{CI}=0.48-$ 0.74) suggesting viral-induced shut-off of host antiviral protein responses. However, proteins for $I P-10(\mathrm{OR}=3.74 \mathrm{CI}=2.07-6.77)$ and several interferon-stimulated genes (ISG) increased with viral load (BST-1 OR =25.1, CI =3.33-188; IFITI OR =19.5, $\mathrm{CI}=4.25-89.2 ;$ IFIT3 OR $=245, \mathrm{CI}=15-4020 ; M X-1 \mathrm{OR}=3.33, \mathrm{CI}=1.44-7.70$ ). Older age was associated with substantial modifications of some effects. Ambulatory symptomatic patients had an innate immune response with SARS-CoV-2 infection characterized by elevated IFN, proinflammatory cytokine and ISG transcripts, but there is evidence of a viral-induced host shut-off of antiviral responses. Our findings may characterize the disrupted immune landscape common in patients with early disease.

\section{K E Y W O R D S}

biomarkers, host shut-off, innate immunity, interferon, SARS-CoV-2

\section{1 | INTRODUCTION}

The coronavirus disease 2019 (COVID-19) pandemic due to severe acute respiratory syndrome (SARS) coronavirus(CoV)-2 infection has afflicted millions following first reports (Timeline: WHO's COVID-19 response, 2020). Rapid molecular characterization of the virus (Corman et al., 2020; Lu, Zhao, et al., 2020; Wu et al., 2020) enabled multiple instances of successful containment using public health measures (Baker et al., 2020; Cheng et al., 2020; Cowling et al., 2020; Fouda et al., 2020; Kang et al., 2020; Wang et al., 2020). Elsewhere, however, viral spread has been rapid, widespread and devastating.

Silent infection with rapid viral replication allows asymptomatic person-to-person infection (Cheng et al., 2020; Kang et al., 2020; Sakurai et al., 2020; Wang, Ng, et al., 2020). Nasopharyngeal viral loads peak when upper airway symptoms appear (Cheng et al., 2020; Wölfel et al., 2020), and the size of the initial viral innoculum may determine the rapidity of onset and severity of the subsequent clinical syndrome (Gandhi et al., 2020). Over days or weeks, the infection may extend to involve the lower respiratory tract. For many patients, initial fever, dry cough, myalgias, and anosmia progress to dyspnea, hypoxemic respiratory failure, and the acute respiratory distress syndrome (ARDS) (Huang et al., 2020; Lescure et al., 2020; Wang, Hu, et al., 2020; Zhou, Yang, et al., 2020). Innate immune dysfunction and systemic inflammatory responses include marked elevations in systemic inflammatory cytokines and insufficient antiviral interferon (IFN) responses that create a cytokine storm (Chen et al., 2020; Pedersen \& Ho, 2020; Wang et al., 2014; Ye et al., 2020; Zhou, Ren, et al., 2020).

Part of the challenge to developing a treatment or prevention response is to narrow the extensive list of potential biochemical treatment targets (Pedersen \& Ho, 2020; Zhang et al., 2020). Evaluations in ARDS due to other severe respiratory viral infections (Chen \& Subbarao, 2007; Gralinski \& Baric, 2015; Jong et al., 2006; Kim et al., 2016; Kindler et al., 2013; Li \& Lin, 2013; Nicholls et al., 2003; Qian et al., 2013; Wang et al., 2014) highlight the broad collection of biomarkers that may potentially be useful in SARS-CoV-2 infection.

Coronaviruses that cause severe human disease are remarkable for their ability to evade innate immune defenses and to promote dysfunctional responses that appear before cytokine storm (Lei \& Hilgenfeld, 2017; Nelemans \& Kikkert, 2019). For example, IFN responses are critically important for antiviral defense (Lazear et al., 2019), yet there is no detectable native human IFN response to SARSCoV (Zielecki et al., 2013). Both SARS-CoV and SARSCoV-2 stimulate inflammatory signals via nuclear factor $\kappa B(N F \kappa B)$ (DeDiego et al., 2014) that recruit polymorphonuclear neutrophils and other immune effector cells to the lung, releasing proteases that may dramatically further increase viral cell entry (Heurich et al., 2014; Hoffmann et al., 2020; Matsuyama et al., 2005). IFN- $\alpha$ and IFN- $\beta$ treatments that bypass some evasion strategies (Zhou, Ren, 
et al., 2020) have been proposed to counter SARS-CoV-2 infection (Mantlo et al., 2020). However, we lack efficacy and safety trials free of observer bias (Cox, 1958a), and no published human data exist for IFN- $\lambda$ therapy.

To supplement the growing information on responses early in infection, we undertook an observational study of deidentified nasopharyngeal swab samples from patients presenting at drive-through testing centers for evaluation of symptoms potentially due to SARS-CoV-2 infection. We selected proteins involved in different steps of human cellular responses to viral invasion for quantitative measurements by multiple methods to understand the impact of targeting by viral evasion activities (DeDiego et al., 2014; Gralinski \& Baric, 2015; Nelemans \& Kikkert, 2019). We selected and measured factors important for understanding viral entry, intracellular detection of viral invasion, production of proinflammatory signals, systemic inflammatory agents, and multiple IFN and IFN-stimulated gene (ISG) responses relative to viral loads to better understand the immune landscape of patients with early disease.

\section{2 | METHODS}

\subsection{Samples and study population}

Our project was reviewed at the University of Utah by both the Institutional Review Board and the Biosafety Committee. An exemption from informed consent was allowed because patient samples were de-identified. All samples were handled in a biosafety level (BSL) 2 capable hood (ThermoFisher Scientific, Waltham, MA, USA) using BSL 3 procedures until virus inactivation and were handled with BSL 2 procedures thereafter.

Randomly selected and completely deidentified, residual nasopharyngeal swab samples from patients presenting for diagnosis of symptoms consistent with COVID-19 during the period of late April through early June of 2020 were included in the study. Clinical testing involved the use of a portion of each sample to test with automated, FDA Emergency Use Authorized real-time polymerase chain reaction (RT-PCR) or transcription-mediated amplification tests for qualitative presence of SARS-CoV-2 RNA. We received sample remainders annotated with age, sex, and qualitative nucleic acid amplification-detection results after being frozen at $-80^{\circ} \mathrm{C}$ for approximately one month.

\section{2 | Initial extraction of human RNA and proteins}

We extracted RNA using Chemagic reagents and Chemagic MSM I extraction platform (Perkin-Elmer, Billerica, MA,
USA) from part of each sample remainder producing sufficient RNA to allow RT-PCR measurement of reference gene Pol2A (mean $C T=32.22$, $\mathrm{SD}=4.86$ ). To exclude potential artifacts due to modified expression of Pol2A with viral infection, we measured $A c t B$ and $G A P D H$ as alternative reference points and found no effects due to infection for any of the genes. Pol2A had the lowest standard error of measurements. Thus, for all other mRNA measurements, we used the Pol2A $C_{T}$ as the reference point to calculate fold change (see Methods for $C_{T}$ definition and usage).

Protease inhibitor cocktail and equal volume of Hank's Balanced Salt solution (Sigma Aldrich) were added to the final portion of the thawed patient samples prior to centrifugation $\left(20,000 \mathrm{~g}\right.$ for $20 \mathrm{~min}$ at $\left.4^{\circ} \mathrm{C}\right)$. We carefully aspirated the supernatant for Bead Based Multiplex Immunoassays. Pellets from centrifugation were extracted using All-Prep Micro kits (Qiagen) in accordance with the manufacturer's instructions, producing additional RNA suitable for RT-PCR and a final protein-containing pellet for Mass Spectrometry.

\section{3 | Real-time polymerase chain reaction of viral and human mRNA}

For most mRNAs, we had a sufficient samples to study all 40 patients; for selected mRNAs, we were able to study six samples with and six samples without SARS-CoV-2 detection. All specific mRNA measurements were based on RT-PCR employing RNA from a single extraction method to avoid technical sources of noise.

An equal amount of RNA was taken for first-strand cDNA reverse transcription (ABI High Capacity cDNA Reverse Transcription Kit) and specific amplification in a StepOnePlus (ABI, ThermoFisher Scientific). Gene-specific primers were designed using the Roche Applied Science Universal Probe Library Assay Design Center. All amplifications were performed using a 2-step amplification protocol with ABI PowerUp SYBR Green Master Mix as follows: 1 cycle at $50^{\circ} \mathrm{C}$ for 2 minutes to activate UDG, 1 cycle at $95^{\circ} \mathrm{C}$ for 2 minutes to release the DNA polymerase then 40 50 cycles with a 3 -second denaturing at $95^{\circ} \mathrm{C}$ followed by 30 -second annealing and denaturing at $60^{\circ} \mathrm{C}$.

A melt curve (dissociation) was performed for every primer to ensure the above amplification conditions resulted in the amplification of a single peak. All of the designed primers gave a single peak upon dissociation after amplification suggesting no nonspecific binding to other genes. Amplification of genomic DNA was prevented by using primers that spanned an intron. The $I F N-\alpha 2$ gene and IFITM-1 ISG do not have introns. The primers did, however, give a single peak upon dissociation. All other primers including $I F N-\lambda$ spanned an intron. 


\section{4 | Bead based multiplex immunoassays}

Cytokine analyses of patient samples were performed using a commercially available enzyme-linked immunosorbent assay (LEGENDplex Human Anti-Virus Response Panel 13-Plex with Filter Plate, BioLegend, San Diego, CA). This bead-based multiplex assay allowed for the simultaneous quantification of interleukins (IL-1 $\beta$, IL-6, IL-8 [or CXCL8], IL-10, IL-12p70); interferons (IFN- $\alpha 2$, IFN- $\beta$, IFN- $\gamma$, IFN- $\lambda 1$, IFN- $\lambda 2,3$ ), TNF- $\alpha$, IP-10 (or CXCL10), and GM-CSF in patient samples using a flow cytometric approach. All standards and samples were assayed in duplicate using manufacturer recommended protocols. Incubation steps were conducted at room temperature with constant agitation $(500 \mathrm{rpm})$, and shielded from exposure to light. Performing the assay in standard 96-well filter plates facilitated thorough washing of samples and required the use of a MultiScreen Vacuum Manifold (EMD Millipore Corporation, Billerica, MA) alongside a uniform vacuum source. Following the final wash of combined sample and biotinylated detection antibodies, bound proteins of interest were re-suspended in $0.008 \%$ final concentration of EM-grade glutaraldehyde (Electron Microscopy Sciences, Hatfield, PA, USA, Cat \#16216) for 48 hours at $4{ }^{\circ} \mathrm{C}$ to inactivate SARS-CoV-2, adapting a protocol previously investigated for SARS-CoV (Darnell et al., 2004). Following incubation, samples were washed a final time and transferred to a polystyrene 96-well plate with conical bottoms. Flow cytometric analysis of cytokines was performed using a BD FACSCanto II system (BD Biosciences, San Jose, CA) at the University of Utah Flow Cytometry Core (Salt Lake City, UT) and analyzed using LEGENDplex software (BioLegend).

\section{5 | Mass spectrometry}

\subsubsection{Preparation of proteins prior to mass spectrometry}

Proteins were reduced with $5 \mathrm{mM}$ dithiothreitol (DTT) at $60^{\circ} \mathrm{C}$ for 45 minutes, followed by alkylation with $10 \mathrm{mM}$ iodoacetamide (IAA) at room temperature for 30 minutes in the dark. Excess IAA was neutralized by the addition of $5 \mathrm{mM}$ DTT. A trypsin/LysC mixture (Promega; Madison, WI) was added to the proteins in a 1:100 ratio and the proteins were digested overnight at $38^{\circ} \mathrm{C}$. The digestion was quenched by acidification of the solution with the addition of $1 \%$ formic acid to a $\mathrm{pH}$ of $2-3$.

Initially, the pelleted proteins from the COVID-19 patients would not completely dissolve in $50 \mathrm{mM}$ ammonium bicarbonate. However, after the trypsin/LysC digestion, all of the samples were completely dissolved in solution. The final concentration of the peptides was determined using a peptide colorimetric assay and the use of a Nanodrop One (ThermoFisher Scientific) spectrophotometer.

\subsubsection{Data-Dependent Acquisition (DDA) nanoLC-MS/MS}

Peptides ( $1 \mu \mathrm{g}$ on column) were loaded using a Dionex UltiMate 3000 RSLCnano system (ThermoFisher Scientific) onto a PharmaFluidics $\mu$ PAC micro-chip based trapping column and separated using a $50 \mathrm{~cm}$ equivalent PharmaFluidics $\mu \mathrm{PAC}$ microchip-based column (PharmaFluidics, Ghent, Belgium). Chromatography was performed using ultrapure water with $0.1 \%$ formic acid (solvent A) and acetonitrile containing $0.1 \%$ formic acid (solvent B). Elution was carried out with an initial mobile phase concentration of $5 \%$ for 4 minutes followed by a ramp to $45 \%$ over 76 minutes then a second ramp to $95 \%$ B in 5 minutes. This was held for 10 minutes followed by ramping down to $5 \% \mathrm{~B}$ over two minutes and re-equilibration for 10 minutes. Flowrate was $0.5 \mathrm{~mL} / \mathrm{min}$. A QExactive HF (ThermoFisher Scientific) coupled to a Flex nanospray source was employed with the following settings for MS1; resolution 60, AGC target 3e6, maximum IT $100 \mathrm{~ms}$, scan range $375-1650 \mathrm{~m} / \mathrm{z}$. MS2 settings were as follows: resolution 15,000, AGC target 2e5, maximum IT $25 \mathrm{~ms}$, isolation window $1.4 \mathrm{~m} / \mathrm{z}$. Top 15 DDA analysis was performed with NCE set to 27.

\subsection{3 | Data-Independent Acquisition (DIA) nanoLC-MS/MS}

Staggered window DIA analysis was carried out using the methods described by (Pino et al., 2020). A peptide centric gas phase retention time library was generated by pooling equal amounts of each sample and analyzing this using six narrow windows. DIA experiments with the following settings for MS1: resolution 60,000, AGC target 1e6, maximum IT 55, with six separate analyses in the following mass ranges $395-505 \mathrm{~m} / \mathrm{z}, 495-605 \mathrm{~m} / \mathrm{z}, 595-705 \mathrm{~m} / \mathrm{z}, 695-805 \mathrm{~m} / \mathrm{z}$, $795-905 \mathrm{~m} / \mathrm{z}$, and $895-1005 \mathrm{~m} / \mathrm{z}$. MS2 analysis used the following settings: resolution 30,000, AGC target 1e6, loop count 25 , default charge 3 , NCE 27 with $4 \mathrm{~m} / \mathrm{z}$ staggered DIA windows. NanoLC-MS/MS analysis was carried out identically to DDA analysis described above.

\subsection{4 | DDA data processing}

The Proteome Discover version 2.4 (ThermoFisher Scientific) precursor-based quantification processing workflow was 
employed. SequestHT with multiple peptide search and percolator validation was employed to extract protein data. The following search options were employed, Homo sapiens FASTA file, trypsin digestion, two missed cleavages, minimum peptide length 6 , precursor mass tolerance $10 \mathrm{ppm}$, fragment mass tolerance $0.02 \mathrm{Da}$, carbamidomethylation of cysteine as a peptide static modification, $\mathrm{N}$-terminal acetylation, $\mathrm{N}$-terminal Met-loss and methionine oxidation as protein dynamic modifications.

\subsection{5 | DIA data processing}

Thermo .RAW files were demultiplexed and converted to mzML files using MSConvert (Chambers et al., 2012). The Walnut functionality of EnclopeDIA (Searle et al., 2018) was employed for peptide centric library creation. Peptides were identified using the same variables as DDA described above. Quantitation was performed using Skyline (MacLean et al., 2010).

\section{6 | Calculations and statistical analysis}

For all mRNA, we calculated fold-change for each sample (FCsample) after measuring the fractional number of polymerase chain reaction doubling cycles required so that SYBR Green fluorescence exceeded the threshold for detection $\left(C_{T}\right)$. We used the following formula:

$$
\text { FCsample }=2^{-\left(\Delta C_{T} \text { sample }-\Delta C_{T} \text { median }\right)}
$$

where $\Delta C_{T}$ sample was the number of doubling cycles to detect each mRNA minus the number of doubling cycles to detect mRNA from the Pol2A reference gene for each sample, and the $\Delta C_{T}$ median was the median $\Delta C_{T}$ sample for samples without detection of SARS-CoV-2. The incorporation of $C_{T}$ for Pol2A mRNA in the calculation indexes the measurement so that samples with different efficiencies of recovery of mRNA containing cells between testing individuals are standardized.

For IFIT-3 fold change values from DIA mass spectrometry, FCsample was calculated:

$$
F C \text { sample }=\frac{A U C_{\text {IFIT3 }}}{\text { median }\left(A U C_{\text {virusnegativeIFIT3 }}\right)}
$$

where $A U C_{I F I T 3}$ is the area under the curve (AUC) for peptides identified as part of IFIT-3, and median $\left(A U C_{\text {virus negative IFIT3 }}\right)$ is the median AUC for IFIT-3 from samples without detection of SARS-CoV-2. The other prespecified ISG proteins were undetectable by DIA mass spectrometry, and thus no fold-change calculation was possible.
We calculated summary statistics. We examined associations between different biomarker measurements by calculating Spearman's rank correlation statistic to better understand potential dependencies. We used log transformations of all mRNA and protein measurements in our statistical calculations because of the log-normal nature of our results. Others using the methods that we employed, however, often report results using either natural or base 2 logs. Because the bulk of our results are commonly reported using natural log values, we standardized on those for reporting. The effect is to slightly change results normally reported using base $2 \log$ by a proportion equal to natural $\log$ of 2 (or 0.698). This usage has no effect on interpretations of results.

Using SARS-CoV-2 infection status as the independent variable, we performed linear regression with natural $\log (F C)$ of each prespecified mRNA or natural $\log \left(F C_{\text {IFIT3 }}\right)$ as the dependent variable because we seek to understand the biological effects of infection. Each univariable model was adjusted with age and sex with backward selection to understand the impacts on model fits. We performed univariable linear regression with natural $\log (F C)$ or natural $\log$ (protein concentration $[\mathrm{pg} / \mathrm{ml}])$ as the dependent variables and natural $\log \left(F C_{\text {viral N1 protein } m R N A}\right)$ as the independent variable to understand associations with viral load, adjusting with age and sex as above.

We performed sensitivity analyses of significant associations. For each dependent biomarker with significant associations with infection status or viral load, we selected all other biomarkers reported to have significant correlations as additional adjustment variables. Using these adjustment biomarkers one at a time, we assessed the impact on the estimates for infection status and viral load for each significant association.

We assigned 50 as the $C_{T}$ value for undetectable mRNA. For undetectable proteins by bead-based multiplex immunoassay, we assigned the minimum detection value. These assignments enable quantitative analysis without treating the values as missing. Results were similar when the analysis was restricted to raw data derived from the six infected and six uninfected samples with the highest recovery of RNA. All calculations and statistical modeling were performed using the R statistical system (R Core Team, 2020).

\section{3 | RESULTS}

\section{1 | Study population}

We evaluated 40 samples from individuals, evenly divided into 20 positive and 20 negative detection results for SARS-CoV-2. Samples were deidentified but annotated by age (median 46.5 years, range 11-90) and sex (17 females, 
(a)

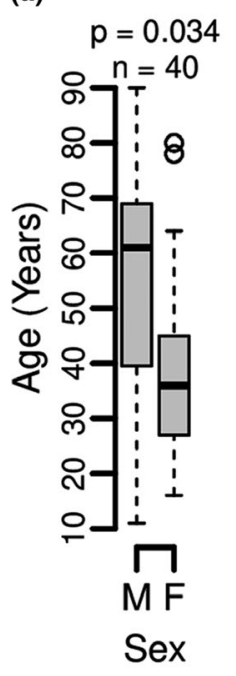

(b)

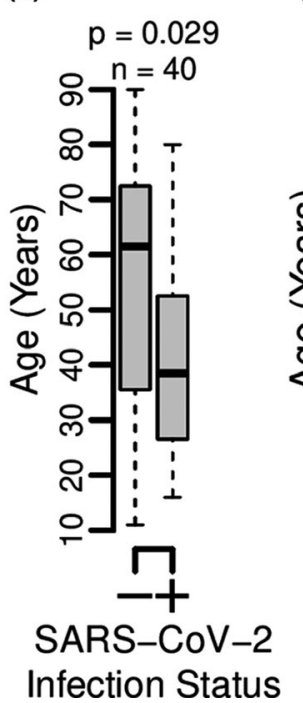

(c)

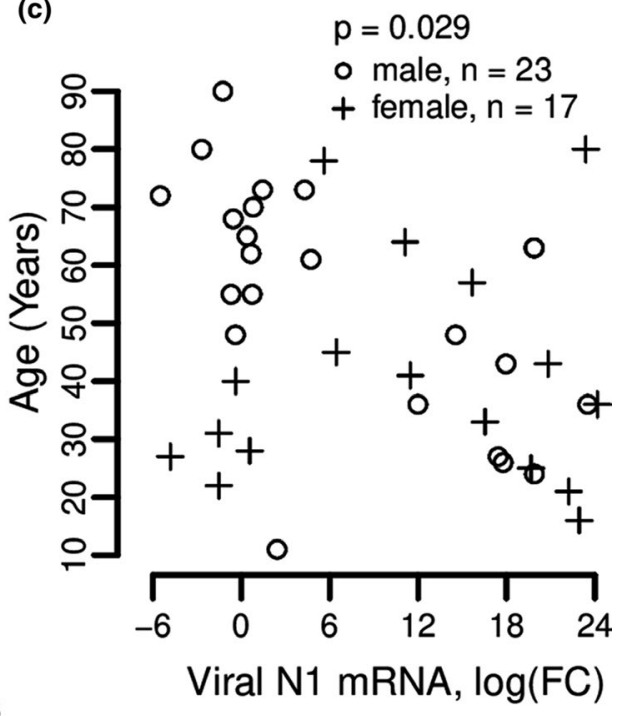

F I G URE 1 Relationships with Age. In $A$ : male patients were older and in $B$ : patients without infection were older, but in $C$ : this relationship is seen to be limited to male patients (see also Table 3). Each box-plot includes boxes that show median, upper, and lower quartile values and whiskers or single points that show upper and lower extremes (McGill et al., 1978); $p$ values were calculated using linear regression (Chambers, 1998).
$42.5 \%$ ). Older patients were more likely to be male and negative for SARS-CoV-2 detection (Figure 1 and Tables 1-3). This limited demographic information suggested that further evaluation of statistical relationships in our sample set required testing adjustments for age, sex, or both to avoid confounding.

Samples included in our study were randomly selected from those collected from April-June of 2020 from patients who may have come from nine states within the Mountain West of the United States. During this period, positive results were

TABLE 1 Demographics.

\begin{tabular}{llll} 
& \multicolumn{2}{l}{$\begin{array}{l}\text { Age Range and } \\
\text { SARS-CoV-2 Status }\end{array}$} & \\
\cline { 2 - 3 } Sex & Not Detected & Detected & n \\
\hline male & $11-90$ & $24-63$ & 23 \\
\cline { 2 - 3 } female & $22-78$ & $16-80$ & 17 \\
\hline $\mathrm{n}$ & 20 & 20 & 40 \\
\hline
\end{tabular}

reported for about $9-10 \%$ of tested patients. Among the positive test patients, about $10 \%$ eventually required hospitalization for COVID-19 with less than $50 \%$ of those hospitalized suffering respiratory failure, ARDS, or succumbing to severe disease. While we know this context for our samples, the specific outcomes for individual patients in our study remain unknown.

\section{2 | Viral load}

Using RT-PCR, we estimated fold-change in mRNA expression of SARS-CoV-2 small envelope protein E1 (Odds Ratio $[\mathrm{OR}]=10.8 \times 10^{6}, 95 \%$ Confidence Interval $\left.[\mathrm{CI}]=8.37 \times 10^{5}-1.40 \times 10^{8}, p<0.001\right)$ and nucleocapsid protein $\mathrm{N} 1\left(\mathrm{OR}=5.1 \times 10^{7}, \mathrm{CI}=4.5 \times 10^{6}-5.9 \times 10^{8}\right.$, $p<0.001)$ relative to expression in patients without infection. We selected primers (Udugama et al., 2020) for $E 1$ originally from Charité, Germany (Corman et al., 2020) and Nl from the US CDC (Lu, Wang, et al., 2020). Both El and N1 mRNA fold changes gave virtually total discrimination between

\begin{tabular}{|lllllll} 
Age Effect & Estimate & SE & $\boldsymbol{t}$ & OR & 95\% CI & $p$ \\
\hline Female & -0.0361 & 0.0177 & -2.04 & 0.965 & $0.932-0.999$ & 0.041 \\
\hline SARS2 Detected & -0.0365 & 0.0174 & -2.09 & 0.964 & $0.932-0.998$ & 0.036 \\
\hline
\end{tabular}

TA BLE 2 Relationships Between Sex and Virus Detection Status with Age ${ }^{\mathrm{a}}$.

${ }^{a}$ Univariable logistic regression models (Cox, 1958b; Hosmer et al., 2013) of age as the input variable with female sex and positive virus detection as output variables. Younger patients are more likely to be female and more likely to be infected.

\begin{tabular}{lllllll} 
Sex & Estimate & SE & $\boldsymbol{t}$ & OR & $\mathbf{9 5 \%}$ CI & $\boldsymbol{p}$ \\
Male & -1.22 & 0.39 & -3.14 & 0.294 & $0.137-0.631$ & $0.005^{\dagger}$ \\
Female & 0.195 & 0.482 & 0.404 & 1.21 & $0.472-3.12$ & 0.692 \\
\hline
\end{tabular}

TA B L E 3 Relationship of Age with Viral Load by Sex ${ }^{\mathrm{a}}$.

${ }^{\mathrm{a}}$ Univariable linear regressions between Age in years as the dependent variable and $\log (\mathrm{FC})$ of viral N1 protein for each sex. 
patients with and without infection diagnosed by clinical testing for SARS-CoV-2 infection using qualitative RT-PCR.

\section{3 | Viral entry}

We measured two human protein transcripts important for understanding SARS-CoV-2 cell entry, angiotensin-converting enzyme-2 (ACE-2), which is essential for entry of SARS-CoV-2 and SARS-CoV (Hoffmann et al., 2020; Shang et al., 2020), and transmembrane protease, serine-2 (TMPRSS-2) which enhances cell entry up to a thousand-fold (Heurich et al., 2014; Hoffmann et al., 2020). ACE-2 mRNA was increased threefold in patients with infection, and the fold-change results were strongly associated with viral load. TMPRSS-2 mRNA expression, however, was not associated with infection nor viral load (Figure 2).

\section{4 | Viral detection signaling}

We examined transcription signals for two genes in the signaling pathway downstream of viral detection important for IFN responses, TNF-associated factor-binding kinase-1 associated with inhibitor of $N F \kappa B(T B K-1)$ and Stimulator of IFN genes-(STING)- 1 for six patients with positive detection of SARS-CoV-2 and six patients with negative detection. The mRNA expressions of $T B K-1$ and STING- 1 were not associated with infection.
F I G URE 2 Association of ACE2 but not TMPRSS2 Expression with SARSCoV-2 Infection. A: ACE-2 mRNA is increased approximately three-fold in patients with SARS-CoV-2 infection over $A C E-2$ mRNA expression in patients without infection, and $B$ : the increase in expression is associated with viral load ( $\mathrm{OR}=1.16, \mathrm{CI}=1.1-1.23, p<0.001)$. However, the expression of TMPRSS-2 is $C$ : neither increased nor decreased with infection and $D$ : is not associated with viral load. Adjustments for age and sex were not significant for either molecule. In each panel, $A-D$, there are six infected and six noninfected status patients. Each box-plot includes boxes that show median, upper, and lower quartile values and whiskers or single points that show upper and lower extremes (McGill et al., 1978), and $p$ values were calculated using linear regression (Chambers, 1998). (a)

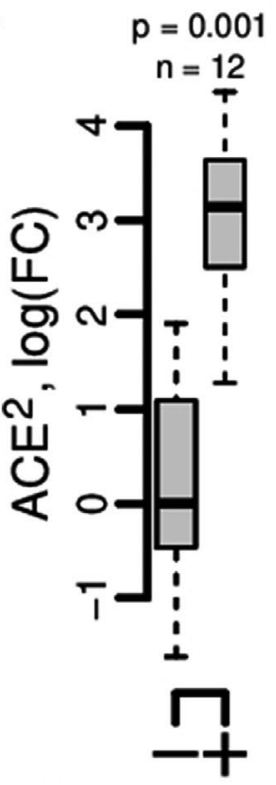

SARS-CoV-2 Infection Status (b)

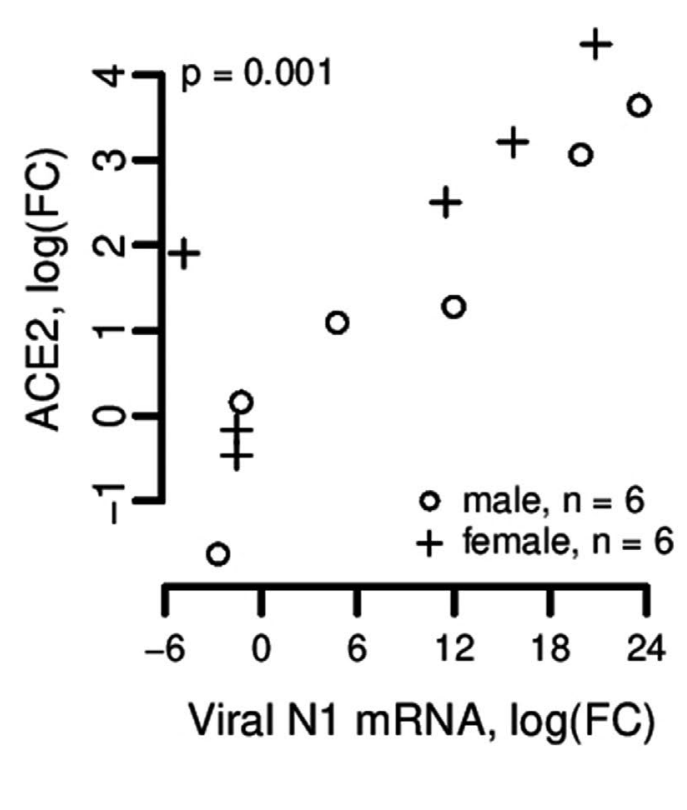

(c)

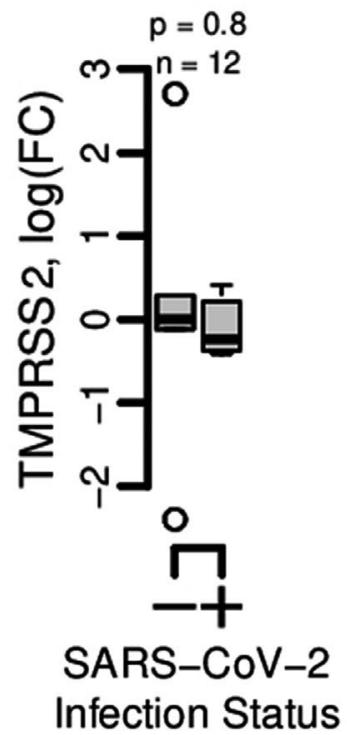

(d)

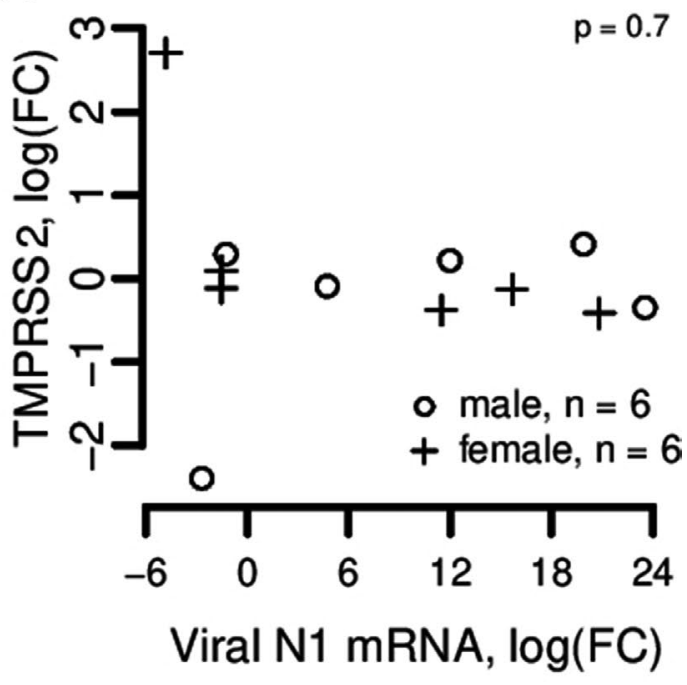




\subsection{Inflammatory responses to SARS- CoV-2 infection}

We found increased mRNA expression of $I L-8, I F N-\gamma-$ induced protein-(IP)-10, and TNF- $\alpha$ in SARS-CoV-2infected individuals (Figure 3A-C). Moreover, we found that there was a strong association between viral load and the level of mRNA expression of these innate immune effector molecules (Figure 3F-H).

Viral entry, detection, and signaling may lead to a systemic inflammatory response via $N F \kappa B$ activity which may potentially be augmented by $T N F$ receptor-associated factor(TRAF)-1 activity (Edilova et al., 2018; Lalani et al., 2018). We found a large reduction in TRAF-1 mRNA (Figure 3D). The reduction in TRAF-1 was inversely associated with expression of both viral protein $E 1$ mRNA (OR $=0.945$, $\mathrm{CI}=0.906-0.986, p=0.025)$ and $N 1$ mRNA $(\mathrm{OR}=0.947$, $\mathrm{CI}=0.907-0.989, p=0.034$, Figure $3 \mathrm{E}$ ). We found $N F \kappa B$ 1 and $N F \kappa B-2$ mRNA transcripts were not significantly changed compared to uninfected status (Table 4). Other downstream immune effectors, granulocyte-macrophage colony-stimulating factor (GM-CSF), IL-6 and IL-10 mRNA were not increased (Table 4).

Protein measurements using bead-based multiplex immunoassays (BioLegend) for systemic inflammatory markers matching many of the mRNAs measured (plus IL-1b and IL12p70) revealed no significant changes with infection and no significant associations with viral load with one exception. IP10 protein was increased nearly fourfold above measured control values (Table 5), and the log of concentration was strongly associated with viral load (OR $=1.09$ per unit of $\log$ unit of viral $N 1$ mRNA fold-change, $\mathrm{CI}=1.06-1.12, p<0.001$ ).

\subsection{IFN responses to infection}

We found five to sixfold increases in expression of both $I F N-\lambda I$ and $I F N-\lambda 2$ mRNA among patients with detection of

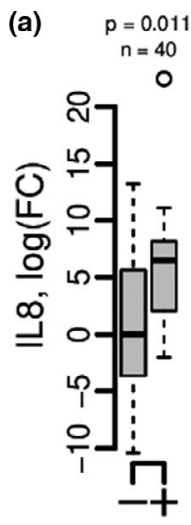

Infection (b)

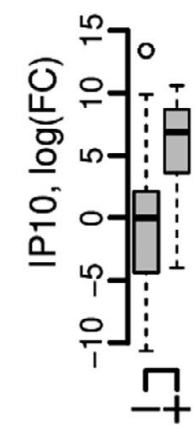

Infection (c)

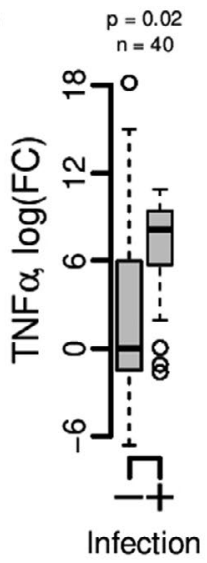

(d)

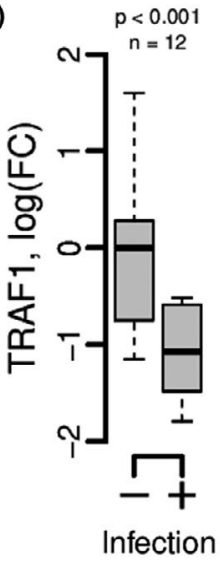

(e)

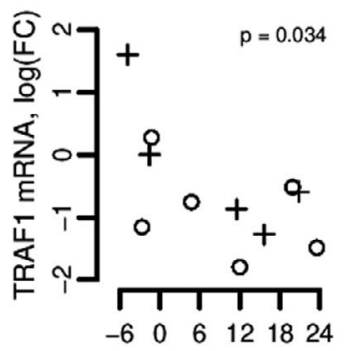

(h)

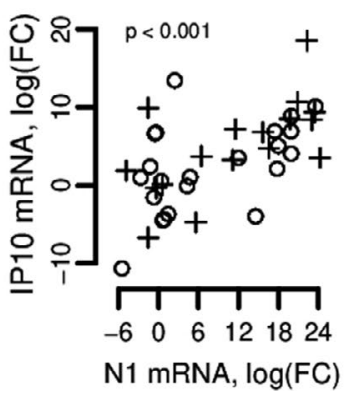

(f)

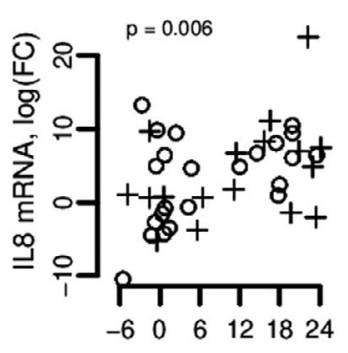

(i)

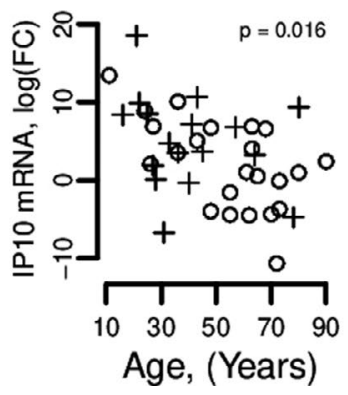

F I G URE 3 Transcripts for Genes Associated with Inflammation. Transcription of $A: I L-8, B: I P-10, C: T N F-\alpha$ mRNA are all increased approximately sixfold, whereas transcription of D:TRAF-1 is reduced. When assessed for relationship with viral load, $E$ : decreasing TRAF-1 mRNA is associated with increasing viral $N 1$ protein mRNA, whereas increasing mRNA for $F$ : $I L-8, G$ : $T N F-\alpha$ (less strongly) and $H: I P-10$ are associated with increasing viral $N 1$ protein mRNA. In contrast, $I$ : decreasing $I P-10$ mRNA is associated with increasing age. Similar relationships are seen in viral $E 1$ protein transcripts (not shown). In each panel, $A-C$, there are 20

\section{infected and 20 noninfected status patients. In panel $D$, there are six infected and six noninfected. Each box-plot includes boxes that show median, upper, and lower quartile values and whiskers or single points that show upper and lower extremes (McGill et al., 1978), and $p$ values were calculated using linear regression (Chambers, 1998). \\ Panel E \\ o male, $n=6$ \\ Panels F-I \\ + female, $n=17$}


TA B L E 4 Systemic Inflammatory mRNA Response to SARS-CoV-2 Infection.
TABLE 5 Protein production of inflammatory markers $(\log [\mathrm{pg} / \mathrm{ml}])$ with SARS-CoV-2 Infection.
TA B L E 6 IFN Response to SARSCoV-2 Infection.

\begin{tabular}{|lclclll} 
mRNA $^{\mathbf{a}}$ & Estimate & SE & t & OR & CI & $p$ \\
\hline$G M-C S F$ & 0.136 & 1.74 & 0.0784 & 1.15 & $0.038-34.6$ & 0.94 \\
$I L-6$ & -1.21 & 2.36 & -0.514 & 0.298 & $0.0029-30.1$ & 0.61 \\
\hline$I L-8$ & 4.93 & 1.83 & 2.69 & 139 & $3.82-5030$ & 0.011 \\
$I L-10$ & 3.94 & 2.01 & 1.97 & 51.5 & $1.01-2620$ & 0.057 \\
\hline$I P-10^{\mathrm{b}}$ & 4.87 & 1.62 & 3.00 & 131 & $5.43-3160$ & 0.005 \\
\hline$N F \kappa B-1$ & 1.4 & 0.956 & 1.47 & 4.07 & $0.625-26.5$ & 0.17 \\
\hline$N F \kappa B-2$ & 1.58 & 2.03 & 0.778 & 4.84 & $0.0909-258$ & 0.46 \\
\hline$T N F-\alpha$ & 4.09 & 1.67 & 2.44 & 59.7 & $2.24-1590$ & 0.019 \\
\hline$T R A F 1$ & -1.08 & 0.442 & -2.45 & 0.339 & $0.143-0.805$ & 0.034 \\
\hline
\end{tabular}

${ }^{\text {a }}$ Results in alphabetical order of mRNA names show natural $\log$ (fold-change in mRNA expression) as the dependent variable and clinical viral detection as the independent variable. Adjustments for age and sex were not significant except as noted. All results were calculated using linear regression (Chambers, 1998).

${ }^{\text {b }}$ Adjustment for sex was not significant, but patients had decreased IP-10 mRNA for each year of additional age $(\mathrm{OR}=0.91,95 \% \mathrm{CI}=0.84-0.98, p=0.016)$.

\begin{tabular}{|lllllll|}
\hline Protein $^{\mathrm{a}}$ & Estimate & SE & $\mathbf{t}$ & OR & CI & \multicolumn{1}{l|}{$\boldsymbol{p}$} \\
\hline GM-CSF & -0.00644 & 0.0060 & -1.07 & 0.994 & $0.982-1.01$ & 0.29 \\
\hline IL-1b & -0.0594 & 0.0358 & -1.66 & 0.942 & $0.878-1.01$ & 0.10 \\
\hline IL-6 & 0.116 & 0.113 & 1.02 & 1.12 & $0.899-1.4$ & 0.32 \\
\hline IL-8 & 0.0976 & 0.457 & 0.214 & 1.1 & $0.45-2.7$ & 0.83 \\
\hline IL-10 & 0.106 & 0.0846 & 1.25 & 1.11 & $0.942-1.31$ & 0.22 \\
\hline IL-12p70 & -0.0888 & 0.078 & -1.14 & 0.915 & $0.785-1.07$ & 0.26 \\
\hline IP-10 & 1.32 & 0.302 & 4.36 & 3.74 & $2.07-6.77$ & $<0.001$ \\
\hline TNF- $\alpha$ & 0.0265 & 0.0265 & 1.00 & 1.03 & $0.975-1.08$ & 0.32 \\
\hline
\end{tabular}

${ }^{\text {a }}$ Results show natural $\log (\mathrm{pg} / \mathrm{ml})$ of each protein as a function of viral detection. Adjustments for age and sex were not significant. All results were calculated using linear regression (Chambers, 1998).

\begin{tabular}{|llllllc|} 
mRNA $^{\mathbf{a}}$ & Estimate $^{\dagger}$ & SE & \multicolumn{1}{l}{$\boldsymbol{t}$} & OR & CI & \multicolumn{1}{c}{$\boldsymbol{p}$} \\
\hline$I F N-\alpha 2$ & 1.17 & 0.993 & 1.17 & 3.21 & $0.458-22.5$ & 0.25 \\
\hline$I F N-\beta 1$ & 0.88 & 1.16 & 0.756 & 2.41 & $0.246-23.6$ & 0.45 \\
\hline$I F N-\gamma$ & 1.89 & 1.03 & 1.84 & 6.65 & $0.883-50.1$ & 0.074 \\
\hline$I F N-\lambda 1$ & 4.26 & 1.18 & 3.62 & 71 & $7.07-713$ & $<0.001$ \\
\hline$I F N-\lambda 2$ & 3.69 & 1.2 & 3.09 & 40.2 & $3.86-419$ & 0.004 \\
$I F N-\lambda 3$ & -0.991 & 2.67 & -0.371 & 0.371 & $0.00196-70.2$ & 0.71 \\
\hline
\end{tabular}

${ }^{\text {a }}$ Results are show natural $\log$ (fold-change in mRNA expression) as a function of viral detection. Adjustments for age and sex were not significant for any model. All results were calculated using linear regression (Chambers, 1998).
SARS-CoV-2 $(\mathrm{n}=20)$ compared to patients without detection of virus $(n=20)$ (Table 6, Figure 4A,C). There were no other significant increases in IFN mRNA. The increases in $I F N-\lambda I$ and $I F N-\lambda 2$ mRNA production were strongly associated with viral load (Table 7 and Figure 4E,F).

Despite increased mRNA expression for some of the IFNs, protein measurements showed reductions in IFN- $\alpha 2$, IFN- $\gamma$, and IFN- $\lambda 2,3$ in patients with viral infection that averaged
$66 \%, 49 \%$, and $40 \%$, respectively, relative to control patients (Table 8).

\subsection{ISG responses to infection}

We prospectively selected four ISGs to evaluate because of their importance in defense against RNA viruses (Sadler 

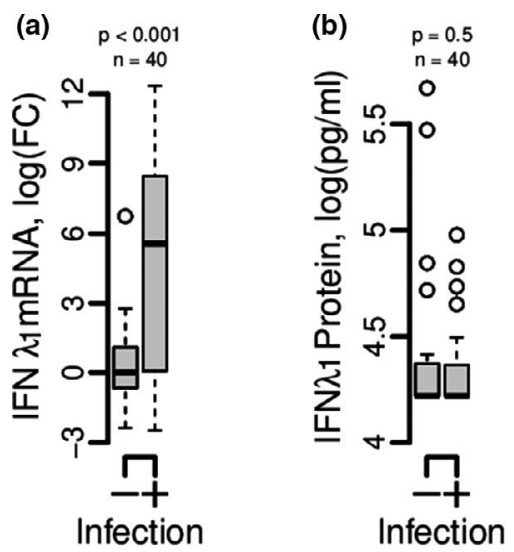

(e)

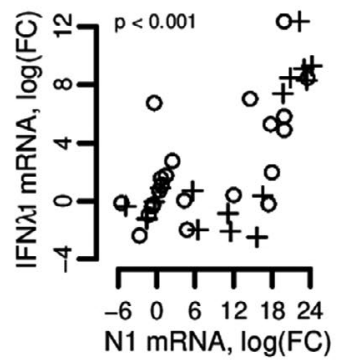

(g)

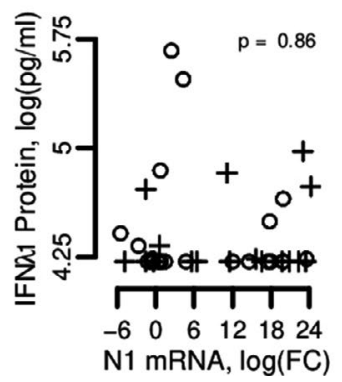

(f)

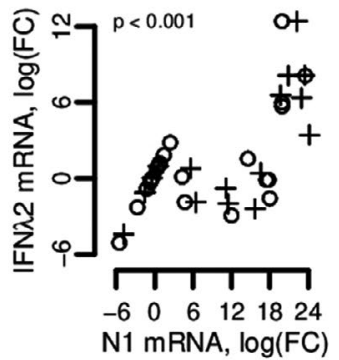

(h)

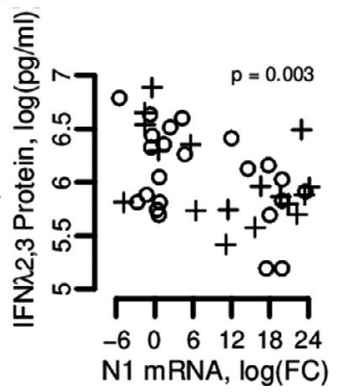

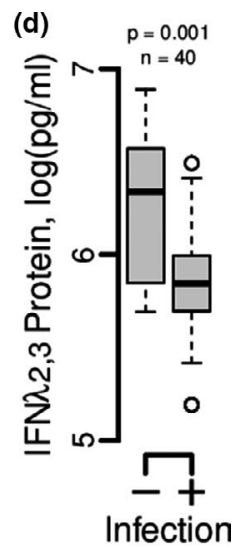

Panels E-H - male, $\mathrm{n}=23$ + female, $n=17$

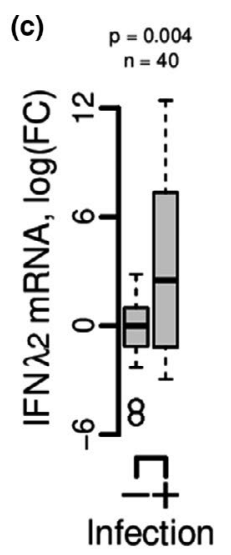

F I G U RE 4 Transcripts for Genes Associated with Interferons. Transcription of $A: I F N-\lambda 1$ is increased nearly sixfold although $B$ : IFN- $\lambda 1$ protein is unchanged with infection. Transcription of $C: I F N-\lambda 2$ is increased about 3 -fold but $D$ : IFN- $\lambda 2$ protein is decreased even if the combined measurement of IFN- $\lambda 2$ and IFN- $\lambda 3$ proteins are attributed solely to IFN $-\lambda 2$. The mRNA fold changes for $E: I F N-\lambda I$ and $F: I F N-\lambda 2$ are directly associated with increasing viral $N 1$ protein mRNA. For $G$ : IFN- $\lambda 1$ protein there is no association with viral $N 1$ protein mRNA, but for $H$ : combined IFN- $\lambda 2$ and IFN- $\lambda 3$ protein measurement, there is an inverse relationship with viral $N 1$ protein mRNA. For $E-H$, substitution of viral $E 1$ mRNA produced similar relationships and figures (not shown). In each panel, $A-D$, there are 20 infected and 20 noninfected status patients. Each box-plot includes boxes that show median, upper, and lower quartile values and whiskers or single points that show upper and lower extremes (McGill et al., 1978), and $p$ values were calculated using linear regression (Chambers, 1998).

TA B L E 7 IFN response associations with viral load (N1 protein).

\begin{tabular}{llllllc} 
mRNA $^{\text {a }}$ & Estimate & SE & $\boldsymbol{t}$ & OR & CI & $\boldsymbol{p}$ \\
\hline$I F N-\alpha 2$ & 0.102 & 0.0495 & 2.06 & 1.11 & $1.01-1.22$ & 0.046 \\
$I F N-\beta 1$ & 0.0904 & 0.0588 & 1.54 & 1.09 & $0.975-1.23$ & 0.13 \\
$I F N-\gamma$ & 0.14 & 0.0507 & 2.75 & 1.15 & $1.04-1.27$ & 0.009 \\
$I F N-\lambda 1$ & 0.302 & 0.0507 & 5.96 & 1.35 & $1.23-1.49$ & $<0.001$ \\
\hline$I F N-\lambda 2$ & 0.285 & 0.0515 & 5.53 & 1.33 & $1.2-1.47$ & $<0.001$ \\
$I F N-\lambda 3$ & 0.0531 & 0.138 & 0.384 & 1.05 & $0.804-1.38$ & 0.70 \\
\hline
\end{tabular}

${ }^{\text {a }}$ Results show linear regression with natural $\log$ (fold-change in mRNA expression) as the dependent variables and natural $\log ($ viral N1) detection as the independent variable. Adjustments for sex and age were not significant for any IFN. All results were calculated using linear regression (Chambers, 1998).

\& Williams, 2008): GTP-binding Myxovirus protein (MX-1) (Haller et al., 2015; Hefti et al., 1999; Kochs \& Haller, 1999; Kochs et al., 2002; Verhelst et al., 2013). IFN-induced proteins with tetratricopeptide repeats (IFIT) (Diamond \& Farzan, 2013), IFN-induced transmembrane protein (IFITM) (Diamond \& Farzan, 2013; Perreira et al., 2013), and Tetherin (BST-2) (Blanco-Melo et al., 2016; Wang et al., 2019). MX-1 and Tetherin mRNA were both increased in infected patients with moderate statistical significance, whereas two IFIT mRNAs were greatly and significantly increased (Table 9). Focused proteomic examination of proteins extracted from samples using DDA mass spectrometry detected an association between positive clinical testing for SARS-CoV-2 and IFIT-1, IFIT-3, and Tetherin proteins with a borderline finding for MX-1 protein (Table 10). Proteomic examination using DIA mass spectrometry, which has less sensitivity but better specificity and precision, detected only a large increase in IFIT-3 
TABLE 8 IFN Protein Production with SARS-CoV-2 Infection.

\begin{tabular}{llllllc} 
Protein $^{\mathrm{a}}$ & Estimate & SE & t & OR & CI & $p$ \\
\hline IFN- $\alpha 2$ & -1.08 & 0.428 & -2.53 & 0.338 & $0.146-0.783$ & 0.016 \\
IFN- $\beta$ & -0.0957 & 0.0838 & -1.14 & 0.909 & $0.771-1.07$ & 0.26 \\
\hline IFN- $\gamma$ & -0.672 & 0.222 & -3.02 & 0.511 & $0.33-0.79$ & 0.004 \\
IFN- $\lambda 1$ & -0.0813 & 0.11 & -0.74 & 0.922 & $0.743-1.14$ & 0.46 \\
\hline IFN- $\lambda 2,3^{\text {b }}$ & -0.520 & 0.115 & -4.52 & 0.595 & $0.475-0.745$ & $<0.001$ \\
\hline
\end{tabular}

${ }^{\text {a }}$ Results show $\log (\mathrm{pg} / \mathrm{ml})$ of each protein as a function of viral detection. Adjustments for sex and age were not significant except as noted. All results were calculated using linear regression (Chambers, 1998).

b Adjustment for sex was not significant, but patients had slightly decreased IFN- $\lambda 2,3$ in response to SARSCoV-2 infection for each additional year of age $(\mathrm{OR}=0.99,95 \% \mathrm{CI}=0.988-0.999, p=0.048)$.

TABLE 9 IFN-stimulated gene transcript responses with SARS-CoV-2 Infection.

\begin{tabular}{|lllllll} 
mRNA $^{\mathbf{a}}$ & Estimate & SE & t & OR & CI & $p$ \\
\hline$B S T-2^{\text {b }}$ & 3.22 & 1.03 & 3.13 & 25.1 & $3.33-188$ & 0.011 \\
\hline$I F I T-1$ & 2.97 & 0.777 & 3.82 & 19.5 & $4.25-89.2$ & 0.003 \\
\hline IFIT-3 & 5.5 & 1.43 & 3.86 & 245 & $15-4020$ & 0.003 \\
\hline IFITM-1 & 0.601 & 0.921 & 0.653 & 1.82 & $0.3-11.1$ & 0.53 \\
\hline MX-1 & 1.2 & 0.427 & 2.82 & 3.33 & $1.44-7.7$ & 0.018 \\
\hline
\end{tabular}

${ }^{a}$ Results show $\log$ (fold change of each mRNA) as a function of viral detection. Adjustments for age and sex were not significant. All results were calculated using linear regression (Chambers, 1998).

${ }^{\text {b }} B S T-2$ is also known as Tetherin.
T A B L E 10 IFN-Stimulated Proteins Using Data-Dependent Acquisition by Mass Spectrometry.

\begin{tabular}{lll} 
Protein $^{\mathrm{a}}$ & $\boldsymbol{\chi}^{2}$ & $\boldsymbol{p}$ \\
\hline BST-2 & 5.48 & 0.019 \\
IFIT-1 & 8.33 & 0.004 \\
\hline IFIT-3 & 8.33 & 0.004 \\
\hline IFITM-1 & - & - \\
\hline MX-1 & 3.375 & 0.066 \\
\hline
\end{tabular}

${ }^{\mathrm{a}} \chi^{2}$ tests (Karl Pearson, 1900) were applied to $2 \times 2$ tables of detection of protein vs detection of SARS-CoV-2 in all cases except for IFIT-1. There was the detection of IFIT-1 in nearly all samples, however, they segregated into high level or low-level detection, and the $\chi^{2}$ test was applied to a $2 \times 2$ table of high detection of protein vs detection of SARS-CoV-2. For each result shown, there were $n=6$ SARS-CoV- 2 negative and $n=6$ SARS-CoV-2 positive patients

${ }^{\mathrm{b}}$ Not Detected.

protein that was associated with clinical infection detection and increasing viral N1 mRNA (Figure 5). Transcript and proteome results are based on the same six positive and six negative samples for which we had sufficient mRNA remaining after other studies.

\section{8 $\quad$ Model adjustments with older age}

The increase in $I P-10$ mRNA with infection was lower in older individuals (Figure 3I). All other things being equal, 10 additional years in age were associated with an approximately overall $70 \%$ reduction in $I P-10$ mRNA compared to controls, whereas 25 additional years in age were associated with an overall $90 \%$ reduction, producing a remarkable counter effect to the infection itself.

We found a borderline significant effect for IFN- $\lambda 2,3$. Patients with older ages have slightly lower IFN- $\lambda 2,3$ per additional year of age with SARS-CoV-2 infection. This small per year effect was associated with a $10 \%$ lower IFN- $\lambda 2,3$ on average for every additional 10 years of age and about $23 \%$ lower IFN- $\lambda 2,3$ for an additional 25 years of age in addition to the approximately $40 \%$ reduction associated with SARSCoV-2 infection (Table 8).

\section{9 | Correlations between IFN, inflammatory and ISG measurements}

We found no strong and significant correlations between any protein and its transcript suggesting widespread translation blockade or rapid protein degradation with two exceptions. Both IP-10 mRNA and protein were directly associated with viral load ( $N 1$ protein mRNA), and the correlation between mRNA and protein was moderate with strong significance, $p<0.001$ (Table 12). IFIT-3 mRNA and protein were strongly associated with viral load (Figure 5E-F) but somewhat weakly correlated with each other (Figure 5G and Table 12). In contrast, we found strong correlations within IFN and inflammatory proteins (Table 11) and within IFN gene, inflammatory signaling gene and ISG transcripts (Table 13). Correlations within IFN 

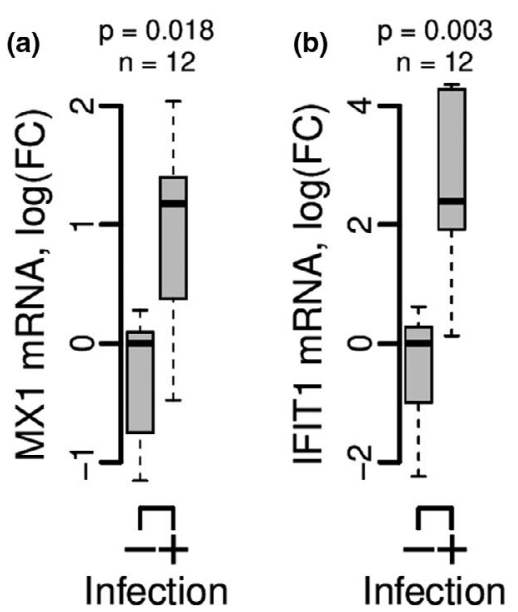

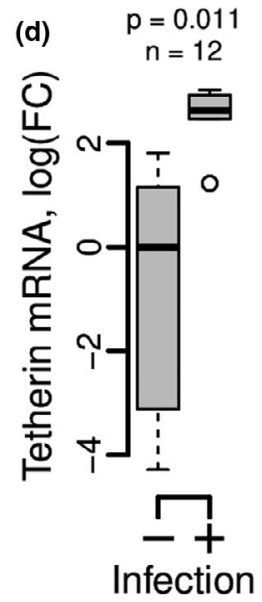

FIGURE 5 Transcripts for Preselected ISGs. Infection with SARS-CoV-2 is associated with increased $A: M X-1, B$ : IFIT-1, C: IFIT-3, and D: Tetherin (BST-2) mRNAs. There were significant associations between increasing $E$ : IFIT-3 mRNA and $F$ : IFIT-3 protein fold changes and increasing viral $N 1$ protein mRNA. Protein fold-change for IFIT-3 was measured using DDA mass spectrometry. Similar relationships were seen using viral $E 1$ protein mRNA as in $E$ and $F$. In each panel, $A-F$, there are six infected and six noninfected status patients. Each box-plot includes boxes that show median, upper, and lower quartile values and whiskers or single points that show upper and lower extremes (McGill et al., 1978), and $p$ values were calculated using linear regression (Chambers, 1998). (e)

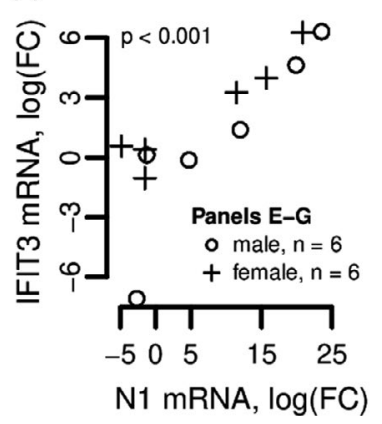

(f)

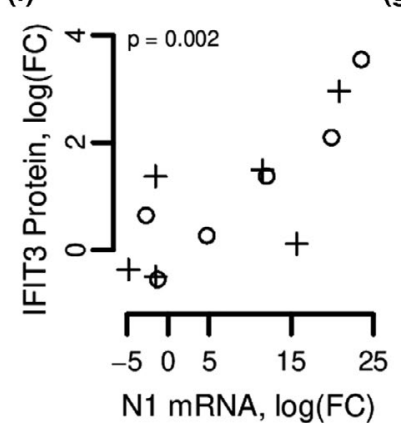

types, for example, among IFN- $\lambda$ subtypes were exceptionally strong which corresponds to the biology of the IFNs.

\subsection{Sensitivity testing}

We performed sensitivity testing for all significant associations between IFN, inflammatory and ISG measurements with viral load ( $N 1$ protein mRNA) by re-examining the relationships after exclusion of patients without infection by SARS-CoV-2. In every case, we found similar relationships between each biomarker and viral load, increasing the confidence in our findings.

Because of the high degree of correlation between some biomarkers (Tables 11-13), for example, between IFN- $\beta 1$ and IFN $\alpha 2$ transcripts (Spearman correlation coefficient $=1.00$, $p<0.001$ ), we examined the effect of adding a second biomarker as an adjustment to the relationship between each significant biomarker $(p<0.05)$ with the clinical diagnosis of infection (Tables 4-6, 8 and 9) or with viral load (Table 7 and individually reported results for ACE2 mRNA, IP-10 mRNA and IP-10 protein in text). In every case, we found similar results for the association between the biomarkers reported and infection status or viral load. A number of the biomarker measurements tested as adjustment variables appeared to have independent significant effects suggesting that significant and independent multivariable associations exist, however, our study is too small to report those results with confidence.

\section{4 | DISCUSSION}

Our results show large increases in transcription of multiple genes involved in innate immune and inflammatory responses soon after SARS-CoV-2 infection and the development of viral-like symptoms (Tables 4, 6, 7, and 9 and Figures 3-5). However, there was a broad-based discrepancy in translation response relative to increased transcription signals similar to the host shut off patterns seen in multiple viruses, including human CoVs such as SARS$\mathrm{CoV}$ that have been reported by many and reviewed by others (Kamitani et al., 2009; Kikkert, 2020; Narayanan et al., 2008; Walsh et al., 2013; Xiao et al., 2008), and that is just beginning to be described in SARS-CoV-2 (Schubert et al., 2020; Thoms et al., 2020). An alternative possibility is that proteins are rapidly degraded after translation, however, either possibility is detrimental to a fully functional innate immune response.

Among the IFNs that we evaluated, several had large increases in transcription that were also strongly associated with viral load (Tables 6-7), but protein production was either unchanged or decreased when comparing samples from symptomatic infected patients to controls with viral-like symptoms not due to SARS-CoV-2 (Table 8). For proinflammatory cytokines, there were similar large increases in transcription (Table 4) but no change in measured protein production except for IP-10 alone (Table 5). Considering that our samples were collected soon after initial symptoms from 


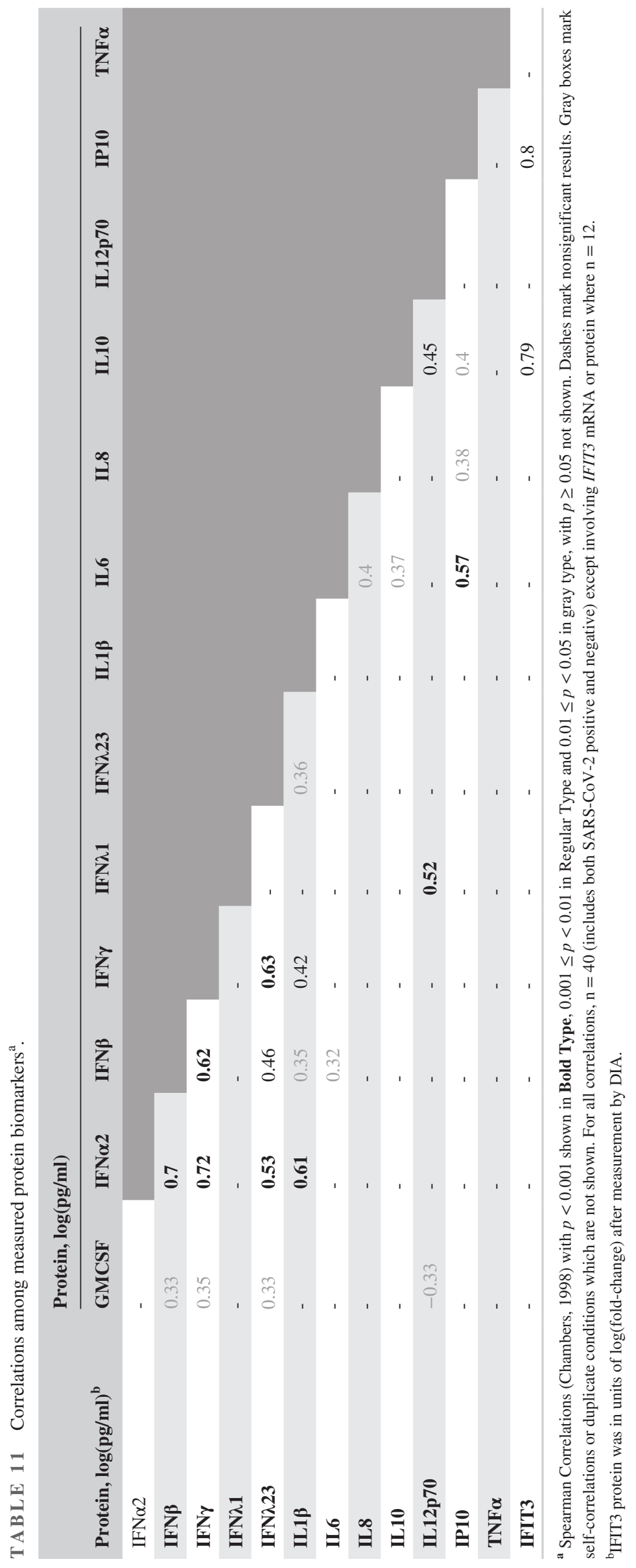




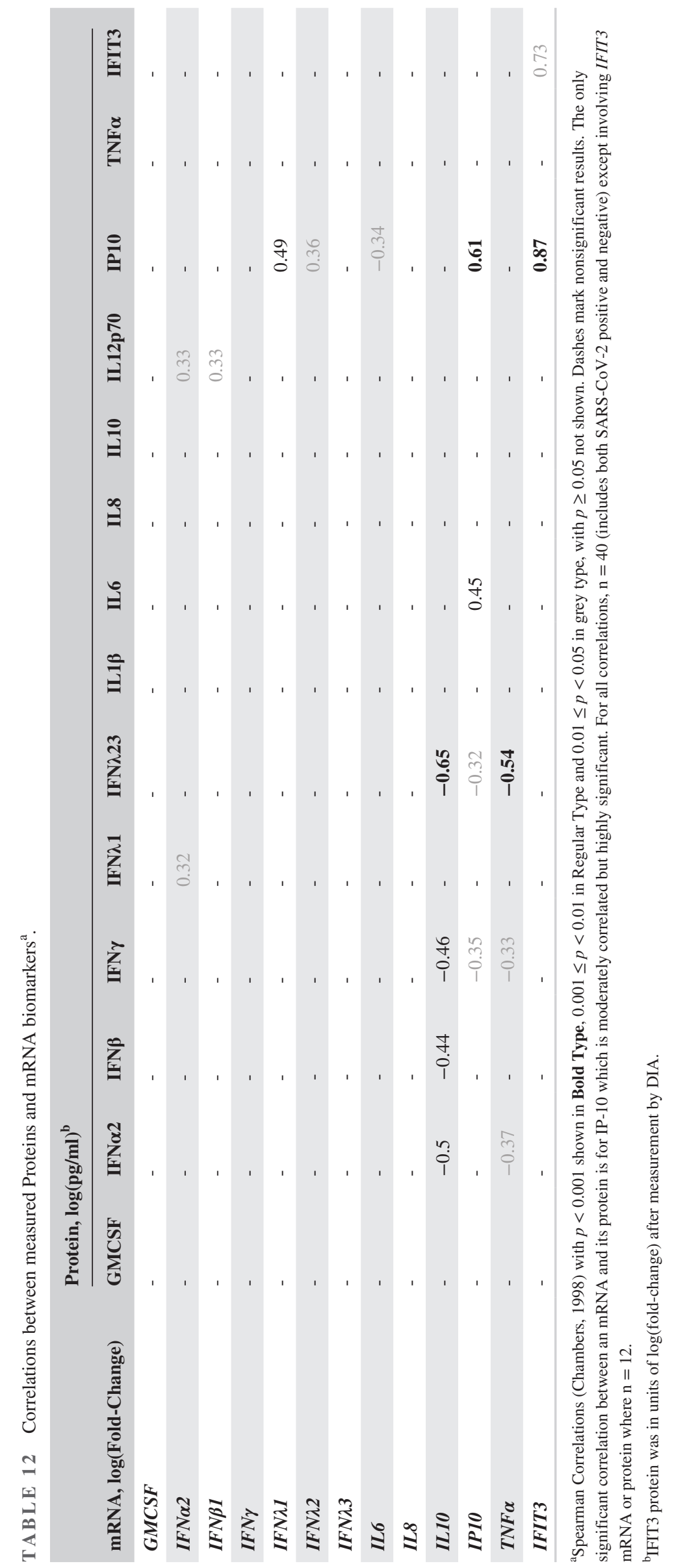


TABLE 13 Correlations among measured mRNA biomarkers ${ }^{\mathrm{a}}$.

\begin{tabular}{|c|c|c|c|c|c|c|c|c|c|c|c|c|}
\hline mRNA, $\log$ (Fold-Change) & \multicolumn{12}{|c|}{ mRNA, log(Fold-Change) } \\
\hline IFN $\beta 1$ & - & 1.00 & & & & & & & & & & \\
\hline$I F N \gamma$ & 0.33 & 0.52 & 0.5 & & & & & & & & & \\
\hline IFN $\lambda 3$ & - & 0.44 & 0.44 & 0.47 & 0.6 & 0.76 & & & & & & \\
\hline IL6 & 0.55 & 0.6 & 0.59 & 0.45 & - & 0.34 & 0.53 & & & & & \\
\hline IL8 & 0.4 & 0.4 & 0.39 & 0.33 & - & - & - & - & & & & \\
\hline IL10 & 0.48 & - & - & 0.4 & - & 0.33 & - & - & 0.33 & & & \\
\hline
\end{tabular}

${ }^{\text {a }}$ Spearman Correlations (Chambers, 1998) with $p<0.001$ shown in Bold Type, $0.001 \leq p<0.01$ in Regular Type and $0.01 \leq p<0.05$ in gray type, with $p \geq 0.05$ not shown. Dashes mark nonsignificant results. Gray boxes mark self-correlations or duplicate conditions which are not shown. For all correlations, $\mathrm{n}=40$ (includes both SARS-CoV-2 positive and negative) except involving IFIT3 mRNA or protein where $\mathrm{n}=12$.

ambulatory patients, the protein production result may indicate that IP-10 is among the first inflammatory proteins to increase early in infection.

The discrepancies between transcription and translation did not fully extend to the ISGs. We selected to evaluate these molecules because of their importance for antiviral defense (Blanco-Melo et al., 2016; Diamond \& Farzan, 2013; Haller et al., 2015; Hefti et al., 1999; Kochs \& Haller, 1999; Kochs et al., 2002; Perreira et al., 2013; Sadler \& Williams, 2008; Verhelst et al., 2013). Observed enormous increases in transcription (Table 9) were accompanied by several large increases in protein production (Table 10). Three antiviral ISGs had increased transcription and translation: IFIT-3 most strongly (Figure 5), IFIT-1 and Tetherin, and there was an additional borderline finding for $M X-1$ (Table 10). Of these ISGs, only IFIT-3 mRNA, however, was weakly correlated ( $p=0.03$ ) with its protein. These findings and the contrast in success of translation when compared with IFNs may be evidence of an IFN independent pathway for IFIT3 protein production (Bandyopadhyay et al., 1995; Liu et al., 2011).

In SARS, suppression of antiviral proteins occurred late in clinical disease (Cheung et al., 2005), however, our results suggest that with SARS-CoV-2, it occurs at the beginning of symptoms. Host translation suppression in SARS is associated with spike protein and nonstructural protein 1 (NSP1) interactions with eukaryotic initiation factor-(eIF)-3 which is required for protein translation (Xiao et al., 2008). Two recent publications investigating mechanisms involving Nsp1 for SARS-CoV-2 showed similar interference with eIF-3 (Schubert et al., 2020; Thoms et al., 2020). Our results add to the in vitro work by demonstrating supportive evidence from early in the clinical course of human infection. Because viruses depend on host mechanisms for translation of viral proteins that are required for assembly of new infectious particles, our observation of continuing transcription and suppressed translation of human proteins may help explain persistent RT-PCR detection of viral RNA but marked decreases in infectious viral particle production soon after the appearance of symptoms. These tentative hypotheses await further development and testing.

ACE-2 mRNA was increased in patients with SARS$\mathrm{CoV}-2$ infection. The finding indicates at least two possible causal relationships. SARS-CoV-2 may selectively infect people with existing high levels of $A C E-2$ transcription, or infection itself may increase transcription of $A C E-2$ above normal. In either case, increased transcription leading to increased protein expression of ACE-2 likely would increase viral entry and thus help amplify viral replication.

We measured transcripts for three intracellular proteins important in pathways leading to IFN production and initiation of $N F \kappa B$-related inflammation. Transcription of $T B K-1$ and $S T I N G-1$ were unchanged, whereas there was a decrease in TRAF-1 mRNA. TRAF-1 is involved in several distinct inflammation-related pathways, but a reduction is most likely associated with increased NFkB activity and subsequently increased systemic inflammation (Lalani et al., 2018). The other two proteins, TBK-1 and STING-1, are important for transmitting detection of viral invasion to processes that produce antiviral IFNs (Lei \& Hilgenfeld, 2017). There was no increase in transcription of STING-1 and TBK-1, however, $I F N-\lambda I$ and $I F N-\lambda 2$ transcripts were markedly elevated (Table 6 and Figure 4). The increases in these transcripts were closely associated with viral load. These findings suggest that detection of viral invasion is successful in generating a signal 
to increase both systemic inflammation and IFN production. Massive and strongly significant increases in $I F N-\lambda I$ and IFN- $\lambda 2$ mRNA (Table 6) may indicate the critical importance of Type III IFNs in SARS-CoV-2 (Andreakos \& Tsiodras, 2020; Davidson et al., 2016; Jewell et al., 2010) even if protein production was decoupled from high levels of gene transcription at the time our samples were collected.

IP-10 was the sole inflammatory cytokine detected with higher protein concentrations in our samples from infected patients (Table 5). IP-10 promotes inflammation in Human Immunodeficiency Virus (Lei et al., 2019), H5 N1 Influenza A (Chan et al., 2005; Jong et al., 2006), Middle-East Respiratory Syndrome virus (Chu et al., 2014) and SARSCoV (Chen \& Subbarao, 2007) infections, thus its prominence early in SARS-CoV-2 infection, while unsurprising, may be important for understanding evolution of disease from initial mildly symptomatic to severe and sometimes fatal. Nevertheless, we found a moderately strong inverse relationship with age such that 10 or 25 additional years of age seemed to be associated with dampening of increases in IP-10 (see Results). This inverse association is at odds with the clinical observation of worsening disease severity associated with older ages and generates questions about the nature of previously observed detrimental effects of IP-10 (Huang et al., 2020; Lescure et al., 2020; Wang, Hu, et al., 2020; Zhou, Yang, et al., 2020) on morbidity and mortality with SARS-CoV-2 infection. Older individuals with COVID-19, for example, may be more sensitive to suppression of antiviral defenses, whereas younger individuals are more sensitive to excessive inflammation. The observations and questions show that abnormal transcript and protein responses to infection cannot be fully interpreted without clinical context drawn from the evaluation of a larger study population.

In contrast to limited but interesting results with adjustments for age, adjustments for sex were uninformative. The lack of significant findings may be due to survivor biases. Ill and severely ill patients are less likely to be female (Huang et al., 2020), but the susceptibility to infection associated with sex remains unknown. Among patients who develop symptoms, innate immune responses may be similar regardless of sex.

Our study is limited by its cross-sectional design, small size, and the nature of the nasopharyngeal swab samples. Due to the urgency of need, we obtained deidentified samples quickly in exchange for giving up detailed clinical annotation. We do not yet have sufficient information to interpret observed abnormalities in IFN and systemic inflammation to seek out associations with clinical outcomes such as respiratory failure or death. However, because a random sample of the population visiting our drive-through diagnosis centers will contain predominantly survivors of infection who never require hospitalization, the measurements we report should roughly represent patients who generally suffer nonsevere disease.
The small size of the study limits our ability to generalize our interpretations and conclusions. Sensitivity analyses, however, increase our confidence in the stability of our findings and suggest that there are additional multivariable associations between biomarkers, infection status, and viral load that may be explored, further strengthening the impression that additional study of more individuals is needed to better understand the extent of innate immune disruptions due to SARS-CoV-2 infection.

Nasopharyngeal swab samples necessarily retrieve a variety of cell types and may retrieve secreted substances that originate elsewhere than the upper airway. Because samples were frozen prior to evaluation, characterization of cell types by cell counting or flow cytometry was not possible. A prospective human study with immediate processing to allow better assessments of cell types present is possible, but the full characterization of secreted molecules will require carefully designed cell culture models to prevent the inclusion of molecules produced elsewhere and transported to the nasopharynx. Two of the genes studied, IFN 22 and IFITM1 do not have introns, thus there is a small chance that our mRNA detection results could have been affected by amplification of genomic DNA despite examining RT-PCR melt curves. However, the results of RT-PCR showed that neither gene transcript was elevated thus our conclusions are unaffected. Finally, identification of other viruses causing presenting symptoms would provide insights on their transmissibility, however, because of small sample sizes, we did not assess for the presence of other viruses such as less pathogenic coronaviruses. More extensive nasopharyngeal sampling is noxious and reduces patient participation, thus future studies that target identification of other viruses may need to consider alternative methods of sampling or detection. Despite the limitations, however, our study provides information highlighting several areas of IFN and inflammatory biology that deserve future investigation.

Although our study identifies strong IFN and systemic inflammatory signal transcription responses to infection, only a larger prospective study incorporating careful annotation of patient characteristics, analysis of serial samples with disease progression and reporting of outcomes can fully assess the clinical implications of these initial findings. Our results overall, even with a small study size, emphasize that there are remarkable disruptions early in disease in the immune landscape. Further study is likely to be both fruitful and illuminating.

\section{ACKNOWLEDGMENTS}

We recognize and thank the many people at the University of Utah who have faced blistering heat, freezing cold, earthquakes, hurricane force winds, forest fire smoke, and the threat of infection to consistently obtain high-quality 
diagnostic samples in service to the community which also supplied the material for our study. This study was funded by the Ben B and Iris M Margolis Family Foundation of Utah and the Claudia Ruth Goodrich Stevens Endowment Fund at the University of Utah. This work was supported by the University of Utah Flow Cytometry Facility in addition to the National Cancer Institute through Award Number 5P30CA042014-24. Proteomics mass spectrometry analysis was performed at the Mass Spectrometry and Proteomics Core Facility at the University of Utah which is supported by U54 DK110858 05. Mass spectrometry equipment was obtained through a Shared Instrumentation Grant 1 S10 OD018210 01A1. Oligonucleotide primers were synthesized by the DNA/Peptide Facility, part of the Health Sciences Center Cores at the University of Utah.

\section{CONFLICT OF INTEREST}

TGL, JLS, and KAP are supported by NIH/NHLBI R01 125520 and by the US Cystic Fibrosis Foundation, Bethesda, MD, grants LIOU13A0, LIOU14P0, LIOU14Y4, LIOU15Y4. During the course of the study, TGL, JLS, and KAP received other support for performing cystic fibrosis-related clinical trials from Abbvie, Inc; Corbus Pharmaceuticals Holdings, Inc; Gilead Sciences, Inc.; Laurent Pharmaceuticals, Inc; Nivalis Therapeutics, Inc; Novartis Pharmaceuticals; Proteostasis Therapeutics, Inc; Savara, Inc; TranslateBio; and Vertex Pharmaceuticals, Inc. None of the funding was provided for the development of vaccines or treatments for SARS-CoV-2 infection. FRA received other support from the National Science Foundation (grant EMSW21-RTG) and NIH (NIH-CSBC: U54 CA20). JEC is supported by NIH/NIDDK U54 DK110858 05. MNH is supported by NIH/NHLBI R01HL137033. CK received support from the UK Medical Research Council. DTL is supported by NIH/ NAIAD R01AI130378. The sponsors of clinical trials and funders of other support played no roles in this study.

\section{AUTHOR CONTRIBUTIONS}

TGL and FRA initiated the project. TGL, FRA, DRC, JEC, MNH, NDH, JLJ, CK, DTL, KAP, ABS, KJW, LJWa, LJWe, and RPIII designed the study. SCH oversaw the drive-through tent clinical testing program. TGL, KEH, SCH, DTL, JLJ, SMS, and KT obtained samples. ABS and EZ performed RTPCR. GJG, MNH, YL, and JEM performed bead-based multianalyte immunoassays. MNH, SMS, YL, and KT extracted RNA. JEC, KT, MNH, SMOS, and YL prepared proteins for mass spectrometry. JEC and SMOS performed mass spectrometry. TGL, FRA, DRC, JEC, and CK analyzed the data. TGL initiated the manuscript writing, but all authors, FRA, BCC, DRC, JEC, GJG, KEH, SCH, NDH, MNH, JLJ, CK, YL, DTL, JEM, EAM, SMOS, KAP, SMS, ABS, KT, KJW, LJWa, LJWe, EZ, and RPIII participated in writing, formulation of interpretations and in revisions. TGL, JEC, JEM, and
RPIII obtained funding. JLJ, KAP, LJWa, and LJWe managed regulatory aspects of the study. Authors are listed in alphabetical order except first and senior (last) authors.

\section{ORCID}

Theodore G. Liou (1) https://orcid.org/0000-0003-0121-4847 Frederick R. Adler (1) https://orcid.org/0000-0002-9022-3157 Barbara C. Cahill (1) https://orcid.org/0000-0001-8767-2149 James E. Cox (1) https://orcid.org/0000-0002-5977-2350 Garett J. Grant (D) https://orcid.org/0000-0002-7266-9964 Kimberly E. Hanson (1) https://orcid.org/0000-0001-9790-277X My N. Helms (1) https://orcid.org/0000-0002-0954-8481 Judy L. Jensen (D) https://orcid.org/0000-0002-5284-4761 Christiana Kartsonaki (1) https://orcid.org/0000-0002-3981-3418 Daniel T. Leung (10 https://orcid.org/0000-0001-8401-0801 Elizabeth A. Middleton (10) https://orcid.org/0000-0002-5120-8202 Salika M. Shakir (D) https://orcid.org/0000-0003-4642-8574 Kristi J. Warren (1) https://orcid.org/0000-0003-0680-4037 Robert Paine (1) https://orcid.org/0000-0002-4511-4437

\section{REFERENCES}

Andreakos, E., \& Tsiodras, S. (2020). COVID-19: lambda interferon against viral load and hyperinflammation [published online ahead of print: 25 2020]. EMBO Molecular Medicine. https://doi. org/10.15252/emmm.202012465

Baker, M. G., Kvalsvig, A., \& Verrall, A. J. (2020). New Zealand's COVID-19 elimination strategy. Medical Journal of Australia, 213(5), 198-200.e1.

Bandyopadhyay, S. K., Leonard, G. T., Bandyopadhyay, T., Stark, G. R., \& Sen, G. C. (1995). Transcriptional induction by double-stranded RNA is mediated by interferon-stimulated response elements without activation of interferon-stimulated gene factor 3. Journal of Biological Chemistry, 270(33), 19624-19629.

Blanco-Melo, D., Venkatesh, S., \& Bieniasz, P. D. (2016). Origins and Evolution of tetherin, an Orphan Antiviral Gene. Cell Host \& Microbe, 20(2), 189-201.

Chambers, J. M. (1998). Programming with data: a guide to the S language. Springer.

Chambers, M. C., Maclean, B., Burke, R., Amodei, D., Ruderman, D. L., Neumann, S., Gatto, L., Fischer, B., Pratt, B., Egertson, J., Hoff, K., Kessner, D., Tasman, N., Shulman, N., Frewen, B., Baker, T. A., Brusniak, M.-Y., Paulse, C., Creasy, D., ... Mallick, P. (2012). A cross-platform toolkit for mass spectrometry and proteomics. Nature Biotechnology, 30(10), 918-920.

Chan, M. C. W., Cheung, C. Y., Chui, W. H., Tsao, S. W., Nicholls, J. M., Chan, Y. O., Chan, R. W. Y., Long, H. T., Poon, L. L. M., Guan, Y., \& Peiris, J. S. M. (2005). Proinflammatory cytokine responses induced by influenza A (H5N1) viruses in primary human alveolar and bronchial epithelial cells. Respiratory Research, 6, 135.

Chen, G., Wu, D. I., Guo, W., Cao, Y., Huang, D., Wang, H., Wang, T., Zhang, X., Chen, H., Yu, H., \& Zhang, X. (2020). Clinical and immunological features of severe and moderate coronavirus disease 2019. The Journal of Clinical Investigation, 130(5), 2620-2629.

Chen, J., \& Subbarao, K. (2007). The Immunobiology of SARS*. Annual Review of Immunology, 25, 443-472.

Cheng, H.-Y., Jian, S.-W., Liu, D.-P., Ng, T.-C., Huang, W.-T., \& Lin, H.-H. (2020). Contact Tracing Assessment of COVID-19 
Transmission Dynamics in Taiwan and Risk at Different Exposure Periods Before and After Symptom Onset [published online ahead of print: May 1, 2020]. JAMA Internal Medicine, 180(9), 1156https://doi.org/10.1001/jamainternmed.2020.2020

Cheung, C. Y., Poon, L. L., Ng, I. H., Luk, W., Sia, S. F., Wu, M. H., Chan, K. H., Yuen, K. Y., Gordon, S., Guan, Y., \& Peiris, J. S. (2005). Cytokine responses in severe acute respiratory syndrome coronavirus-infected macrophages in vitro: Possible relevance to pathogenesis. Journal of Virology, 79(12), 7819-7826.

Chu, H., Zhou, J., Wong, B. H. Y., Li, C., Cheng, Z. S., Lin, X., Poon, V. K. M., Sun, T., Lau, C. C. Y., Chan, J. F. W., \& To, K. K. W. (2014). Productive replication of Middle East respiratory syndrome coronavirus in monocyte-derived dendritic cells modulates innate immune response. Virology, 454-455, 197-205.

Corman, V. M., Landt, O., Kaiser, M., Molenkamp, R., Meijer, A., Chu, D. K. W., Bleicker, T., Brünink, S., Schneider, J., Schmidt, M. L., Mulders, D. G. J. C., Haagmans, B. L., van der Veer, B., van den Brink, S., Wijsman, L., Goderski, G., Romette, J.-L., Ellis, J., Zambon, M., ... Drosten, C. (2020). Detection of 2019 novel coronavirus (2019-nCoV) by real-time RT-PCR. Eurosurveillance Weekly, 25(3), https://doi.org/10.2807/1560-7917.ES.2020.25.3.2000045

Cowling, B. J., Ali, S. T., Ng, T. W. Y., Tsang, T. K., Li, J. C. M., Fong, M. W., Liao, Q., Kwan, M. Y. W., Lee, S. L., Chiu, S. S., Wu, J. T., Wu, P., \& Leung, G. M. (2020). Impact assessment of nonpharmaceutical interventions against coronavirus disease 2019 and influenza in Hong Kong: an observational study. Lancet Public Health, 5(5), e279-e288.

Cox, D. R. (1958a). Planning of Experiments. Wiley.

Cox, D. R. (1958b). The Regression Analysis of Binary Sequences. Journal of the Royal Statistical Society Series B (Methodological), 20(2), 215-242.

Darnell, M. E. R., Subbarao, K., Feinstone, S. M., \& Taylor, D. R. (2004). Inactivation of the coronavirus that induces severe acute respiratory syndrome, SARS-CoV. Journal of Virological Methods, 121(1), 85-91.

Davidson, S., Davidson, S., McCabe, T. M., Crotta, S., Gad, H. H., Hessel, E. M., Beinke, S., Hartmann, R., \& Wack, A. (2016). IFN $\lambda$ is a potent anti-influenza therapeutic without the inflammatory side effects of IFN $\alpha$ treatment. EMBO Molecular Medicine, 8(9), 1099-1112.

de Jong, M. D., Simmons, C. P., Thanh, T. T., Hien, V. M., Smith, G. J. D., Chau, T. N. B., Hoang, D. M., Van Vinh Chau, N., Khanh, T. H., Dong, V. C., Qui, P. T., Van Cam, B., Ha, D. Q., Guan, Y., Peiris, J. S. M., Chinh, N. T., Hien, T. T., \& Farrar, J. (2006). Fatal outcome of human influenza A (H5N1) is associated with high viral load and hypercytokinemia. Nature Medicine, 12(10), 1203-1207.

DeDiego, M. L., Nieto-Torres, J. L., Jimenez-Guardeño, J. M., ReglaNava, J. A., Castaño-Rodriguez, C., Fernandez-Delgado, R., Usera, F., \& Enjuanes, L. (2014). Coronavirus virulence genes with main focus on SARS-CoV envelope gene. Virus Research, 194, 124-137.

Diamond, M. S., \& Farzan, M. (2013). The broad-spectrum antiviral functions of IFIT and IFITM proteins. Nature Reviews Immunology, 13(1), 46-57.

Edilova, M. I., Abdul-Sater, A. A., \& Watts, T. H. (2018). TRAF1 Signaling in Human Health and Disease. Frontiers in Immunology, 9, 2969

Fouda, A., Mahmoudi, N., Moy, N., \& Paolucci, F. (2020). The COVID-19 pandemic in Greece, Iceland, New Zealand, and
Singapore: Health policies and lessons learned [published online ahead of print: August 28, 2020]. Health Policy and Technology, 9(4), 510-524. https://doi.org/10.1016/j.hlpt.2020.08.015

Gandhi, M., Beyrer, C., \& Goosby, E. (2020). Masks Do More Than Protect Others During COVID-19: Reducing the Inoculum of SARS-CoV-2 to Protect the Wearer [published online ahead of print: July 31, 2020]. Journal of General Internal Medicine, 35(10), 3063-3066. https://doi.org/10.1007/s11606-020-06067-8

Gralinski, L. E., \& Baric, R. S. (2015). Molecular pathology of emerging coronavirus infections. The Journal of Pathology, 235(2), 185-195.

Haller, O., Staeheli, P., Schwemmle, M., \& Kochs, G. (2015). Mx GTPases: dynamin-like antiviral machines of innate immunity. Trends in Microbiology, 23(3), 154-163.

Hefti, H. P., Frese, M., Landis, H., Di Paolo, C., Aguzzi, A., Haller, O., \& Pavlovic, J. (1999). Human MxA protein protects mice lacking a functional alpha/beta interferon system against La crosse virus and other lethal viral infections. Journal of Virology, 73(8), 6984-6991.

Heurich, A., Hofmann-Winkler, H., Gierer, S., Liepold, T., Jahn, O., \& Pöhlmann, S. (2014). TMPRSS2 and ADAM17 cleave ACE2 differentially and only proteolysis by TMPRSS2 augments entry driven by the severe acute respiratory syndrome coronavirus spike protein. Journal of Virology, 88(2), 1293-1307.

Hoffmann, M., Kleine-Weber, H., Schroeder, S., Krüger, N., Herrler, T., Erichsen, S., Schiergens, T. S., Herrler, G., Wu, N.-H., Nitsche, A., Müller, M. A., Drosten, C., \& Pöhlmann, S. (2020). SARS-CoV-2 Cell Entry Depends on ACE2 and TMPRSS2 and Is Blocked by a Clinically Proven Protease Inhibitor. Cell, 181(2), 271-280.e8.

Hosmer, D. W. Jr, Lemeshow, S., \& Sturdivant, R. X. (2013). Applied Logistic Regression. John Wiley \& Sons, Inc.

Huang, C., Wang, Y., Li, X., Ren, L., Zhao, J., Hu, Y., Zhang, L., Fan, G., Xu, J., Gu, X., Cheng, Z., Yu, T., Xia, J., Wei, Y., Wu, W., Xie, X., Yin, W., Li, H., Liu, M., ... Cao, B. (2020). Clinical features of patients infected with 2019 novel coronavirus in Wuhan, China. Lancet, 395(10223), 497-506.

Jewell, N. A., Cline, T., Mertz, S. E., Smirnov, S. V., Flaño, E., Schindler, C., Grieves, J. L., Durbin, R. K., Kotenko, S. V., \& Durbin, J. E. (2010). Lambda interferon is the predominant interferon induced by influenza A virus infection in vivo. Journal of Virology, 84(21), 11515-11522.

Kamitani, W., Huang, C., Narayanan, K., Lokugamage, K. G., \& Makino, S. (2009). A two-pronged strategy to suppress host protein synthesis by SARS coronavirus Nsp1 protein. Nature Structural \& Molecular Biology, 16(11), 1134-1140.

Kang, J., Jang, Y. Y., Kim, J., Han, S. H., Lee, K. R., Kim, M., \& Eom, J. S. (2020). South Korea's responses to stop the COVID-19 pandemic. American Journal of Infection Control, 48(9), 1080-1086.

Karl Pearson, X. (1900). On the criterion that a given system of deviations from the probable in the case of a correlated system of variables is such that it can be reasonably supposed to have arisen from random sampling. The London, Edinburgh, and Dublin Philosophical Magazine and Journal of Science, 50(302), 157-175.

Kikkert, M. (2020). Innate Immune Evasion by Human Respiratory RNA Viruses. Journal of Innate Immunity, 12(1), 4-20.

Kim, E. S., Choe, P. G., Park, W. B., Oh, H. S., Kim, E. J., Nam, E. Y., Na, S. H., Kim, M., Song, K. H., Bang, J. H., \& Park, S. W. (2016). Clinical Progression and Cytokine Profiles of Middle East Respiratory Syndrome Coronavirus Infection. Journal of Korean Medical Science, 31(11), 1717-1725. 
Kindler, E., Jónsdóttir, H. R., Muth, D., Hamming, O. J., Hartmann, R., Rodriguez, R., Geffers, R., Fouchier, R. A., Drosten, C., Müller, M. A., \& Dijkman, R. (2013). Efficient replication of the novel human betacoronavirus EMC on primary human epithelium highlights its zoonotic potential. MBio, 4(1), e00611-00612.

Kochs, G., \& Haller, O. (1999). Interferon-induced human MxA GTPase blocks nuclear import of Thogoto virus nucleocapsids. Proceedings of the National Academy of Sciences of the United States of America, 96(5), 2082-2086.

Kochs, G., Janzen, C., Hohenberg, H., \& Haller, O. (2002). Antivirally active MxA protein sequesters La Crosse virus nucleocapsid protein into perinuclear complexes. Proceedings of the National Academy of Sciences of the United States of America, 99(5), 3153-3158.

Lalani, A. I., Zhu, S., Gokhale, S., Jin, J., \& Xie, P. (2018). TRAF molecules in inflammation and inflammatory diseases. Current Pharmacology Reports, 4(1), 64-90.

Lazear, H. M., Schoggins, J. W., \& Diamond, M. S. (2019). Shared and Distinct Functions of Type I and Type III Interferons. Immunity, 50(4), 907-923.

Lei, J., \& Hilgenfeld, R. (2017). RNA-virus proteases counteracting host innate immunity. FEBS Letters, 591(20), 3190-3210.

Lei, J., Yin, X., Shang, H., \& Jiang, Y. (2019). IP-10 is highly involved in HIV infection. Cytokine, 115, 97-103.

Lescure, F.-X., Bouadma, L., Nguyen, D., Parisey, M., Wicky, P. H., Behillil, S., Gaymard, A., Bouscambert-Duchamp, M., Donati, F., Le Hingrat, Q., \& Enouf, V. (2020). Clinical and virological data of the first cases of COVID-19 in Europe: a case series. The Lancet Infectious Diseases, 20(6), 697-706.

Li, S.-W., \& Lin, C.-W. (2013). Human coronaviruses: Clinical features and phylogenetic analysis. Biomedicine (Taipei), 3(1), 43-50.

Liu, X.-Y., Chen, W., Wei, B., Shan, Y.-F., \& Wang, C. (2011). IFNinduced TPR protein IFIT3 potentiates antiviral signaling by bridging MAVS and TBK1. The Journal of Immunology, 187(5), 2559-2568.

Lu, R., Zhao, X., Li, J., Niu, P., Yang, B., Wu, H., Wang, W., Song, H., Huang, B., Zhu, N., Bi, Y., Ma, X., Zhan, F., Wang, L., Hu, T., Zhou, H., Hu, Z., Zhou, W., Zhao, L., ... Tan, W. (2020). Genomic characterisation and epidemiology of 2019 novel coronavirus: implications for virus origins and receptor binding. Lancet, 395(10224), 565-574.

Lu, X., Wang, L., Sakthivel, S. K., Whitaker, B., Murray, J., Kamili, S., Lynch, B., Malapati, L., Burke, S. A., Harcourt, J., Tamin, A., Thornburg, N. J., Villanueva, J. M., \& Lindstrom, S. (2020). US CDC Real-Time Reverse Transcription PCR Panel for Detection of Severe Acute Respiratory Syndrome Coronavirus 2. Emerging Infectious Diseases, 26(8), https://doi.org/10.3201/eid2608.201246

MacLean, B., Tomazela, D. M., Shulman, N., Chambers, M., Finney, G. L., Frewen, B., Kern, R., Tabb, D. L., Liebler, D. C., \& MacCoss, M. J. (2010). Skyline: an open source document editor for creating and analyzing targeted proteomics experiments. Bioinformatics, 26(7), 966-968.

Mantlo, E., Bukreyeva, N., Maruyama, J., Paessler, S., \& Huang, C. (2020). Antiviral activities of type I interferons to SARS-CoV-2 infection. Antiviral Research, 179, 104811.

Matsuyama, S., Ujike, M., Morikawa, S., Tashiro, M., \& Taguchi, F. (2005). Protease-mediated enhancement of severe acute respiratory syndrome coronavirus infection. Proceedings of the National Academy of Sciences of the United States of America, 102(35), 12543-12547.
McGill, R., Tukey, J. W., \& Larsen, W. A. (1978). Variations of Box Plots. The American Statistician, 32(1), 12-16.

Narayanan, K., Huang, C., Lokugamage, K., Kamitani, W., Ikegami, T., Tseng, C.-T.-K., \& Makino, S. (2008). Severe acute respiratory syndrome coronavirus nsp1 suppresses host gene expression, including that of type I interferon, in infected cells. Journal of Virology, 82(9), 4471-4479.

Nelemans, T., \& Kikkert, M. (2019). Viral Innate Immune Evasion and the Pathogenesis of Emerging RNA Virus Infections. Viruses, 11(10), 961.

Nicholls, J. M., Poon, L. L. M., Lee, K. C., Ng, W. F., Lai, S. T., Leung, C. Y., Chu, C. M., Hui, P. K., Mak, K. L., Lim, W., Yan, K. W., Chan, K. H., Tsang, N. C., Guan, Y., Yuen, K. Y., \& Malik Peiris, J. (2003). Lung pathology of fatal severe acute respiratory syndrome. Lancet, 361(9371), 1773-1778.

Pedersen, S. F., \& Ho, Y.-C. (2020). SARS-CoV-2: a storm is raging [published online ahead of print: March 27, 2020]. Journal of Clinical Investigation, 130(5), 2202-2205. https://doi.org/10.1172/JCI137647

Perreira, J. M., Chin, C. R., Feeley, E. M., \& Brass, A. L. (2013). IFITMs restrict the replication of multiple pathogenic viruses. Journal of Molecular Biology, 425(24), 4937-4955.

Pino, L. K., Just, S. C., MacCoss, M. J., \& Searle, B. C. (2020). Acquiring and Analyzing Data Independent Acquisition Proteomics Experiments without Spectrum Libraries. Molecular \& Cellular Proteomics: MCP, 19(7), 1088-1103.

Qian, Z., Travanty, E. A., Oko, L., Edeen, K., Berglund, A., Wang, J., Ito, Y., Holmes, K. V., \& Mason, R. J. (2013). Innate immune response of human alveolar type II cells infected with severe acute respiratory syndrome-coronavirus. American Journal of Respiratory Cell and Molecular Biology, 48(6), 742-748.

R Core Team (2020). R: A language and environment for statistical computing [Internet]. R Foundation for Statistical Computing.

Sadler, A. J., \& Williams, B. R. G. (2008). Interferon-inducible antiviral effectors. Nature Reviews Immunology, 8(7), 559-568.

Sakurai, A., Sasaki, T., Kato, S., Hayashi, M., Tsuzuki, S.-I., Ishihara, T., Iwata, M., Morise, Z., \& Doi, Y. (2020). Natural History of Asymptomatic SARS-CoV-2 Infection. New England Journal of Medicine, 383(9), 885-886.

Schubert, K., Karousis, E. D., Jomaa, A., Scaiola, A., Echeverria, B., Gurzeler, L.-A., Leibundgut, M., Thiel, V., Mühlemann, O., \& Ban, N. (2020). SARS-CoV-2 Nsp1 binds the ribosomal mRNA channel to inhibit translation. Nature Structural \& Molecular Biology, 27(10), 959-966.

Searle, B. C., Pino, L. K., Egertson, J. D., Ting, Y. S., Lawrence, R. T., MacLean, B. X., Villén, J., \& MacCoss, M. J. (2018). Chromatogram libraries improve peptide detection and quantification by data independent acquisition mass spectrometry. Nature Communications, 9(1), 5128.

Shang, J., Wan, Y., Luo, C., Ye, G., Geng, Q., Auerbach, A., \& Li, F. (2020). Cell entry mechanisms of SARS-CoV-2 [published online ahead of print: May 6, 2020]. Proceedings of the National Academy of Sciences USA, 117(21), 11727-11734. https://doi. org/10.1073/pnas.2003138117

Thoms, M., Buschauer, R., Ameismeier, M., Koepke, L., Denk, T., Hirschenberger, M., Kratzat, H., Hayn, M., Mackens-Kiani, T., Cheng, J., Straub, J. H., Stürzel, C. M., Fröhlich, T., Berninghausen, O., Becker, T., Kirchhoff, F., Sparrer, K. M. J., \& Beckmann, R. (2020). Structural basis for translational shutdown and immune evasion by the Nsp1 protein of SARS-CoV-2. Science, 369(6508), $1249-1255$. 
Timeline: WHO's COVID-19 response [Internet]. Retrieved from https://www.who.int/emergencies/diseases/novel-coronavirus2019/interactive-timeline

Udugama, B., Kadhiresan, P., Kozlowski, H. N., Malekjahani, A., Osborne, M., Li, V. Y. C., Chen, H., Mubareka, S., Gubbay, J. B., \& Chan, W. C. W. (2020). Diagnosing COVID-19: The Disease and Tools for Detection. ACS Nano, 14(4), 3822-3835.

Verhelst, J., Hulpiau, P., \& Saelens, X. (2013). Mx proteins: Antiviral gatekeepers that restrain the uninvited. Microbiology and Molecular Biology Reviews, 77(4), 551-566.

Walsh, D., Mathews, M. B., \& Mohr, I. (2013). Tinkering with translation: protein synthesis in virus-infected cells. Cold Spring Harbor Perspectives in Biology, 5(1), a012351.

Wang, C. J., Ng, C. Y., \& Brook, R. H. (2020). Response to COVID-19 in Taiwan [published online ahead of print: March 3, 2020]. JAMA, 323(14), 1341-https://doi.org/10.1001/jama.2020.3151

Wang, D., , Hu, B., Hu, C., Zhu, F., Liu, X., Zhang, J., Wang, B., Xiang, H., Cheng, Z., Xiong, Y., Zhao, Y., Li, Y., Wang, X., \& Peng, Z. (2020). Clinical Characteristics of 138 Hospitalized Patients With 2019 Novel Coronavirus-Infected Pneumonia in Wuhan, China. JAMA, 323(11), 1061-1069.

Wang, S.-M., Huang, K.-J., \& Wang, C.-T. (2019). Severe acute respiratory syndrome coronavirus spike protein counteracts BST2mediated restriction of virus-like particle release. Journal of Medical Virology, 91(10), 1743-1750.

Wang, Z., Zhang, A., Wan, Y., Liu, X., Qiu, C., Xi, X., Ren, Y., Wang, J., Dong, Y., Bao, M., Li, L., Zhou, M., Yuan, S., Sun, J., Zhu, Z., Chen, L., Li, Q., Zhang, Z., Zhang, X., ... Xu, J. (2014). Early hypercytokinemia is associated with interferon-induced transmembrane protein-3 dysfunction and predictive of fatal H7N9 infection. Proceedings of the National Academy of Sciences of the United States of America, 111(2), 769-774.

Wölfel, R., Corman, V. M., Guggemos, W., Seilmaier, M., Zange, S., Müller, M. A., Niemeyer, D., Jones, T. C., Vollmar, P., Rothe, C., Hoelscher, M., Bleicker, T., Brünink, S., Schneider, J., Ehmann, R., Zwirglmaier, K., Drosten, C., \& Wendtner, C. (2020). Virological assessment of hospitalized patients with COVID-2019. Nature, 581(7809), 465-469.
Wu, F., Zhao, S., Yu, B., Chen, Y.-M., Wang, W., Song, Z.-G., Hu, Y., Tao, Z.-W., Tian, J.-H., Pei, Y.-Y., Yuan, M.-L., Zhang, Y.-L., Dai, F.-H., Liu, Y., Wang, Q.-M., Zheng, J.-J., Xu, L., Holmes, E. C., \& Zhang, Y.-Z. (2020). A new coronavirus associated with human respiratory disease in China. Nature, 579(7798), 265-269.

Xiao, H., Xu, L. H., Yamada, Y., \& Liu, D. X. (2008). Coronavirus spike protein inhibits host cell translation by interaction with eIF3f. PLoS One, 3(1), e1494.

Ye, Q., Wang, B., \& Mao, J. (2020). The pathogenesis and treatment of the Cytokine Storm ' in COVID-19 [published online ahead of print: April 10, 2020]. Journal of Infection, 80(6), 607-613. https://doi.org/10.1016/j.jinf.2020.03.037

Zhang, X., Tan, Y., Ling, Y., Lu, G., Liu, F., Yi, Z., Jia, X., Wu, M., Shi, B., Xu, S., \& Chen, J. (2020). Viral and host factors related to the clinical outcome of COVID-19. Nature, 1-4.

Zhou, P., Yang, X. L., Wang, X. G., Hu, B., Zhang, L., Zhang, W., Si, H. R., Zhu, Y., Li, B., Huang, C. L., \& Chen, H. D. (2020). A pneumonia outbreak associated with a new coronavirus of probable bat origin. Nature, 579(7798), 270-273.

Zhou, Z., Ren, L., Zhang, L., Zhong, J., Xiao, Y., Jia, Z., Guo, L., Yang, J., Wang, C., Jiang, S., \& Yang, D. (2020). Heightened Innate Immune Responses in the Respiratory Tract of COVID-19 Patients [published online ahead of print: May 4, 2020]. Cell Host \& Microbe, 27(6), 883-890.e2. https://doi.org/10.1016/j.chom.2020.04.017

Zielecki, F., Weber, M., Eickmann, M., Spiegelberg, L., Zaki, A. M., Matrosovich, M., Becker, S., \& Weber, F. (2013). Human cell tropism and innate immune system interactions of human respiratory coronavirus EMC compared to those of severe acute respiratory syndrome coronavirus. Journal of Virology, 87(9), 5300-5304.

How to cite this article: Liou TG, Adler FR, Cahill $\mathrm{BC}$, et al. SARS-CoV-2 innate effector associations and viral load in early nasopharyngeal infection. Physiol Rep. 2021;9:e14761. https://doi.org/10.14814/ phy2.14761 